\title{
Flow Instability in Parallel Channels with Water at Supercritical Pressure: A Review
}

\author{
Edward Shitsi*, Seth Kofi Debrah, Vincent Yao Agbodemegbe, Emmanuel Ampomah-Amoako \\ Department of Nuclear Engineering, Graduate School of Nuclear and Allied Sciences, University of Ghana, \\ Accra, Ghana \\ Email: ^edwardshitsi@yahoo.com, s.debrah@gaecgh.org, vincevalt@gmail.com,emmagaec@gmail.com
}

How to cite this paper: Shitsi, E., Debrah, S.K., Agbodemegbe, V.Y. and Ampomah-Amoako, E. (2018) Flow Instability in Parallel Channels with Water at Supercritical Pressure: A Review. World Journal of Engineering and Technology, 6, 128-160. https://doi.org/10.4236/wjet.2018.61008

Received: December 13, 2017

Accepted: February 11, 2018

Published: February 14, 2018

Copyright $\odot 2018$ by authors and Scientific Research Publishing Inc. This work is licensed under the Creative Commons Attribution International License (CC BY 4.0).

http://creativecommons.org/licenses/by/4.0/

\begin{abstract}
Research into flow instability at both subcritical and supercritical pressures has attracted attention in recent years because of its potential of occurrence in industrial heat transfer systems. Flow instability has the potential to affect the safety of design and operation of heat transfer equipment. Flow instability is therefore undesirable and should be avoided in the design and operation of industrial equipment. Rahman et al. reviewed studies on supercritical water heat transfer with the aim of providing references for SCWR researchers. It was found out that most of the CFD studies and experimental studies were performed with single tube geometry due to the complexity of parallel channel geometry. Because studies performed with parallel channel geometry could provide detailed information to the design of the SCWR core, they called for more studies in parallel channel geometry at supercritical pressures in the future. In order to help understand how flow instability investigations are carried out and also highlight the need to understand flow instability phenomenon and equip the designers and operators of industrial heat transfer equipment with the needed knowledge on flow instability, this study carried out a review of flow instability in parallel channels with water at supercritical pressures.
\end{abstract}

\section{Keywords}

Parallel Channels, Supercritical Pressure, Flow Instability, Supercritical Water Cooled Reactor

\section{Introduction}

The growing demand for clean energy for domestic, industrial and other uses for socio-economic gains cannot be over-emphasized. Because of this growing de- 
mand for energy, several studies have been devoted to Generation IV reactors including Supercritical Water Cooled Reactor SCWR proposed purposely for power or electricity generation in the near future. Though SCWR system has a potential of increasing thermal efficiency, issues such as materials to withstand high temperature and pressure conditions for design and construction, heat transfer and flow instability related problems have to be dealt with before its deployment for energy generation [1] [2] [3] [4] [5].

Studies have shown that SCWR has a potential of experiencing flow instability similar to instability that occurs in the two-phase flow systems [6]-[12]. Various studies have shown that flow instability of a system occurs as a results of dramatic variations of the fluid properties at the vicinity of critical and pseudo critical regions at supercritical pressures as shown in Figure 1 [11] [12] [13] [14] [15].

As studies have shown that the efficiency of light water reactors can be improved considerably from $33 \%$ at subcritical pressures to $45 \%$ at supercritical pressures, stability of the operation of SCWR at the supercritical conditions has become a major concern to the nuclear engineers worldwide, especially around the pseudo-critical point where dramatic change of the fluid properties is experienced. Instability is undesirable as high amplitude sustained flow oscillations beyond uncontrollable limits may cause forced mechanical vibration of components, and also disturb control systems and cause operational problems in nuclear reactors [8] [16].

A system is considered to be stable if it goes back to the original steady state following a perturbation or a disturbance in one form or another. In other words, the original steady state of a system is the solution of the system if the

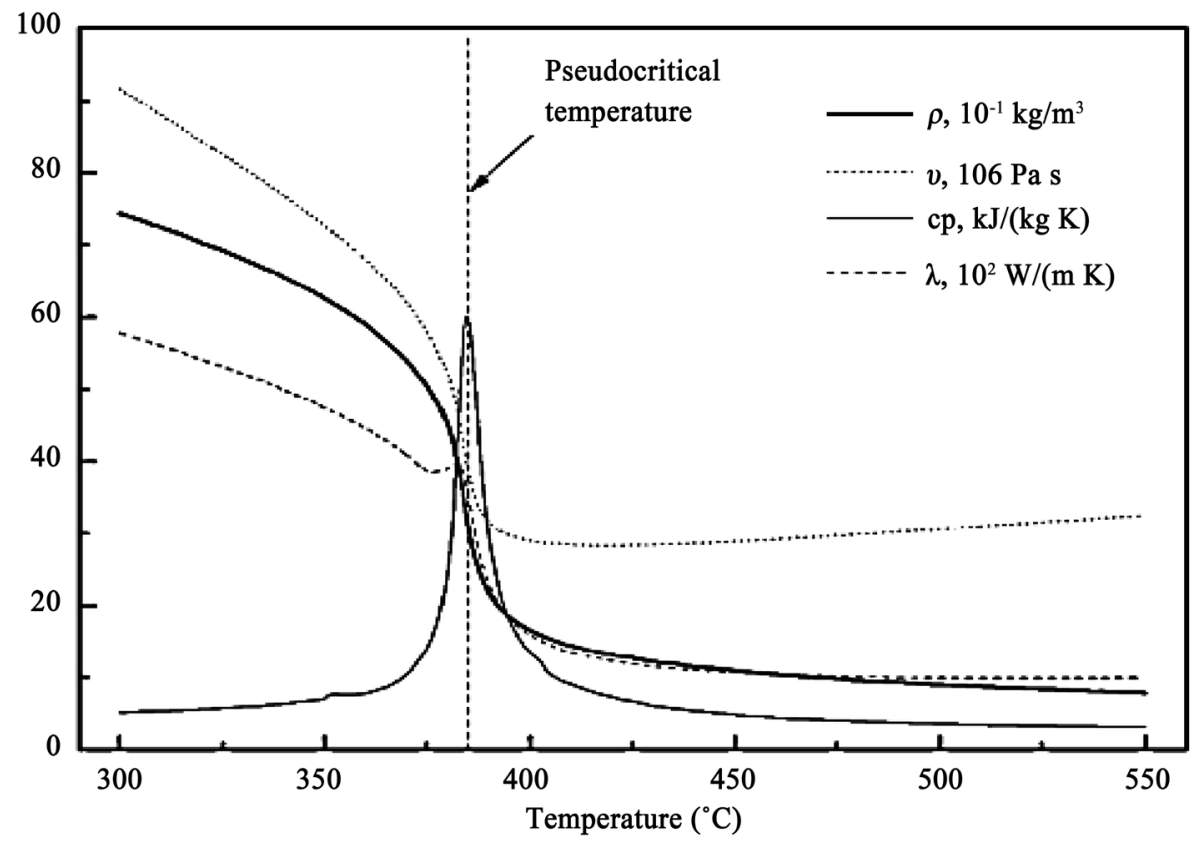

Figure 1. Thermo-physical property variation of water at $25 \mathrm{MPa}$ [13]. 
system is disturbed and is producing slight perturbations that damp out to produce the original steady state. A system is neutrally stable if the system continues to oscillate with the same amplitude. A system is said to be unstable if it stabilizes to a new steady state or if the system oscillation continues with growing amplitude following a perturbation or a disturbance. However, it should be noted that the oscillations amplitudes cannot continue growing indefinitely for a system which is unstable. The oscillations usually form repetition patterns in forms of limit cycle oscillations. These cycle oscillations that are eventually established in the unstable system could be periodic or chaotic because of nonlinearities of the system. Because of growing nature of the oscillation amplitudes, it becomes necessary to quantify some percentage value of the oscillation amplitude below which the system stability is stable and above which the system stability is unstable based on the steady state value. This quantification of flow oscillation is needed to make it possible for numerical and experimental studies to be able to determine whether the system flow is stable or unstable. Some authors recommend that amplitude values more than $\pm 10 \%$ or $\pm 30 \%$ should indicate that the system is unstable [8] [16].

From theoretical and experimental studies, it is well known that for dynamical systems where two phase flow occurs like BWRs there are operational points (OP) in which unstable behavior is observed. Instabilities of such systems can be subdivided into two main classes. These are:

1) Static instabilities (mostly thermal-hydraulic oscillations) and

2) Dynamic instabilities (mostly thermal-hydraulic and neutron kinetic-thermal hydraulic coupled oscillations).

A static instability is the instability type of a system having its original operating conditions moving towards new operating conditions which is not the same as the initial original operation conditions if the flow of the system is disturbed. A dynamic instability is the instability type which occurs as a result of sufficient interaction and delayed feedback between the inertia of flow and compressibility of the two-phase mixture or occurs as a result of multiple feedbacks between flow rate, pressure-drop and the change in density due to generation of vapor in the boiling system. These two static and dynamic instability types are normally classified as thermal-hydraulic instability. But flow instability is also caused by multiple feedback interactions that involve neutron flux fluctuations normally referred to as void-reactivity feedback. The dynamic instability as a result of void-reactivity feedback is normally referred to as nuclear coupled instability. Dynamic instabilities are characterised by either self-sustained periodic or diverging oscillations of the state variables. Examples of dynamic instabilities are density wave oscillations, pressure-drop oscillations, acoustic instabilities, thermal oscillations, condensation-induced instabilities (appearing in thermal-hydraulic-systems) and power oscillations (neutron kinetic - thermal hydraulic coupled oscillations). Table 1 shows some selected Static and Dynamic Instabilities [8] [16]-[24]. Description of these instability types can be found in the mentioned literatures. 
In the context of the nonlinear BWR stability analysis, dynamic instabilities, in particular power oscillations of coupled Thermal-Hydraulic-neutron kinetic systems are of paramount interest. The coupled neutronic and thermal-hydraulic power oscillation can be categorized into the global instability (Core-wide instability) and into the regional instability. In the first mode, the global core power oscillates in-phase, while in the regional oscillating mode, the power in a half core oscillates in an out-of-phase mode with respect to the other half [19] [20]. The physical mechanism behind stable and unstable oscillatory behavior is based on the nonlinear character of the hydraulic equations and on the nonlinear coupling between the neutron kinetics and the thermal hydraulics via void and Doppler feedback reactivity [17].

In the stability diagram (power flow map) associated with BWRs, the unstable flow or power oscillations occur in the low-flow high power region. For safety of design and operations of systems prone to flow or power excursions, this region should be avoided during normal operation. There is possibility of safety limit values including critical power ratio being exceeded which could lead to failure of system design materials giving rise to various flow or power excursions events especially when the amplitudes of flow or power oscillations become too large. These situations could lead to failure of monitoring systems [17] [23]. Table 2 describes some selected events of BWR Core Instabilities [25] [26].

Generally, the three similar dimensionless parameters based on 1D model used to describe flow instability boundary are provided by Gómez et al. [27], Ambrosini and Sharabi [28], and Zhao et al. [29]. The one by Ambrosini is represented as:

$$
\text { Trans-pseudo-critical number : } N_{T P C}=\frac{\beta_{P C}}{C_{P, P C}} \frac{Q_{t}}{M_{t}}
$$

Table 1. Some selected Static and Dynamic Instabilities [8] [16]-[24].

\begin{tabular}{ll}
\hline \multicolumn{1}{c}{ STATIC INSTABILITY } & \multicolumn{1}{c}{ DYNAMIC INSTABILITY } \\
\hline 1) Ledinegg (flow excursion) instability & 1) Acoustic oscillations \\
2) Thermal (boiling crisis) instability & 2) Density wave oscillations \\
3) Flow pattern (regime) transition instability & 3) Thermal oscillations \\
$\begin{array}{ll}\text { 4) Interfacial instabilities } & \text { 4) Boiling water reactor (BWR) instability } \\
\text { 5) Burnout and Quenching instability } & \text { 5) Parallel channel instability } \\
\text { 6) Unstable vapour formation } & \text { 6) Condensation oscillation } \\
\text { (bumping, geysering, vapor burst) } & \text { 7) Pressure drop oscillation } \\
\text { 7) Condensation Chugging } & \text { 8) Channel instability } \\
\text { 8) Flashing instability } & \text { 9) Core-wide instability } \\
\text { 9) Non-equilibrium-state instability } & \text { 10) Regional instability } \\
\text { 10) Flow distribution instability } & \end{array}$
\end{tabular}


Table 2. Events of BWR Core Instabilities [25] [26].

\begin{tabular}{|c|c|c|c|}
\hline Date & Plant & Location & Event (as described by the operator) \\
\hline 30.06 .82 & Caorso & Italy & Core instability during plant start up \\
\hline 01.10 .83 & Caorso & Italy & Core instability during special tests \\
\hline 13.01 .84 & Caorso & Italy & Instability after pump trip \\
\hline 17.10 .84 & S. Maria de Garona & Spain & Power oscillations during operation \\
\hline 23.02 .87 & TVO 1 & Finland & Power oscillations during plant start up \\
\hline 09.03 .88 & La Salle 2 & USA & $\begin{array}{l}\text { Core instability with scram caused } \\
\text { by neutron flux oscillation }\end{array}$ \\
\hline 29.10 .88 & Vermont Yankee & USA & Power oscillations \\
\hline 26.10 .89 & Ringhals 1 & Sweden & Instability during power ascent after refueling \\
\hline 08.01 .89 & Oskarshamn & Sweden & Power oscillations \\
\hline 29.01 .91 & Cofrentes & Spain & $\begin{array}{l}\text { Power oscillations due to inadvertent entry in the } \\
\text { reactor power-core flow map instability zone "B" }\end{array}$ \\
\hline 03.07 .91 & Isar 1 & Germany & Scram due to power oscillations \\
\hline 15.08 .92 & WNP & USA & Power oscillations \\
\hline 09.07 .93 & Perry & USA & Entry into a region of core instability \\
\hline 01.1995 & Laguna Verde & Spain & Power oscillations during start-up \\
\hline 17.07.96 & Forsmark 1 & Sweden & Local oscillations due to a bad seated fuel assembly \\
\hline 08.02 .98 & Oskarshamn 3 & Sweden & $\begin{array}{l}\text { Power oscillations due to a bad combination of core } \\
\text { design and control-rod pattern during start up }\end{array}$ \\
\hline 25.02 .99 & Oskarshamn 2 & Sweden & $\begin{array}{l}\text { Power oscillations after a turbine trip with pump } \\
\text { runback }\end{array}$ \\
\hline--11.01 & Philippsburg-1 & Germany & In-phase power oscillation \\
\hline
\end{tabular}

$$
\text { Subcooling pseudo-critical number : } N_{S P C}=\frac{\beta_{P C}}{C_{P, P C}}\left(h_{P C}-h_{i n}\right)
$$

The one by Gómez is represented as:

$$
\begin{gathered}
\text { Phase change number : } N_{P C H}=\frac{v_{f g} q^{\prime \prime} P_{H} L_{H}}{h_{f g} A_{x-s} v_{f} G} \\
\text { Subcooling number }: N_{S U B}=\frac{\left(v_{L_{H}}-v_{i n}\right)}{v_{i n}} \frac{\left(h_{\lambda}-h_{i n}\right)}{\left(h_{L_{H}}-h_{i n}\right)}
\end{gathered}
$$

And the one by Zhao is represented as:

$$
\begin{gathered}
\text { Expansion number : } N_{\text {exp }}=\frac{R}{P C_{p}} \frac{q^{\prime \prime} P_{h}}{A_{c}} \frac{L}{u_{i n}} \\
\text { Pseudo Subcooling number : } N_{p s u b}=\frac{\left(h_{A}-h_{\text {in }}\right)}{h_{A B}} \frac{\rho_{A}-\rho_{B}}{\rho_{B}}
\end{gathered}
$$

$\beta_{p c}(1 / \mathrm{K}), C_{p, p c}(\mathrm{~J} /(\mathrm{kg} \mathrm{K}))$ and $h_{p c}(\mathrm{~J} / \mathrm{kg})$ are respectively volume expansivity, 
specific heat and enthalpy at pseudo-critical point; and $Q_{t}(\mathrm{~W}), M_{t}(\mathrm{~kg} / \mathrm{s})$ and $h_{i n}$ are respectively total heating power, total mass flow rate and inlet enthalpy of the coolant. $A_{x-s}$ is the cross-sectional flow area $\left(\mathrm{m}^{2}\right), A_{c}$ is the fuel assembly cross sectional flow area $\left(\mathrm{m}^{2}\right), C_{p}$ is the specific heat capacity $(\mathrm{J} /(\mathrm{kg} \mathrm{K})), G$ is mass flux $\left(\mathrm{kg} / \mathrm{m}^{2} \mathrm{~s}\right), h$ is enthalpy $(\mathrm{J} / \mathrm{kg}), h_{L_{H}}$ is enthalpy at the exit of the heated length $(\mathrm{J} / \mathrm{kg}), h_{\lambda}$ is reference enthalpy $(\mathrm{J} / \mathrm{kg}), h_{f}$ is the enthalpy of saturated liquid $(\mathrm{J} / \mathrm{kg}), h_{f g}$ is the latent heat $(\mathrm{J} / \mathrm{kg}), N$ is the characteristic non-dimensional number, $N_{P C H}$ is the phase change number, $N_{S P C}$ is the subpseudo-critical number, $N_{S U B}$ subcooling number, $N_{T P C}$ is the true trans-pseudocritical number, $p$ is the system pressure $(\mathrm{Pa}), P_{\mathrm{H}}$ is the heated perimeter $(\mathrm{m}), P_{h}$ is the fuel rods outside perimeter per fuel assembly $(\mathrm{m}), q^{\prime \prime}$ is the uniform axial heat flux $\left(\mathrm{W} / \mathrm{m}^{2}\right), R$ is the ideal gas constant $(\mathrm{J} /(\mathrm{mol} \mathrm{K})), v$ is the specific volume $\left(\mathrm{m}^{3} / \mathrm{kg}\right), v_{f}$ is the specific volume of saturated liquid $\left(\mathrm{m}^{3} / \mathrm{kg}\right), v_{f g}$ is the difference between $v_{g}$ and $v_{f}\left(\mathrm{~m}^{3} / \mathrm{kg}\right), v_{g}$ is the specific volume of saturated vapor $\left(\mathrm{m}^{3} / \mathrm{kg}\right)$, and $v_{L_{H}}$ is the specific volume at the exit of the heated length $\left(\mathrm{m}^{3} / \mathrm{kg}\right)$.

These 1D dimensionless parameters cannot be adopted to describe flow instability boundary in 3D analysis because of assumptions made in their derivations including the frictional pressure drop coefficient $\xi$ is thought to be constant which is different from reality [11] [12]. According to Xi et al. [11] [12], the coolant inlet temperature and the ratio of heating power (threshold or critical power) to inlet mass flow rate are adopted to obtain the instability boundary for $3 \mathrm{D}$ analysis. But some studies also adopted the parameters, heating power or heating flux against inlet enthalpy or inlet temperature to obtain the instability boundary for 3-D analysis [30] [31] [32]. Figure 2 and Figure 3 respectively show Dimensionless and Dimensional stability diagrams for describing flow instability of a system. Operating conditions to the left of the instability boundary curves are referred to as "Stable region" to operate a system. Similarly, the operating

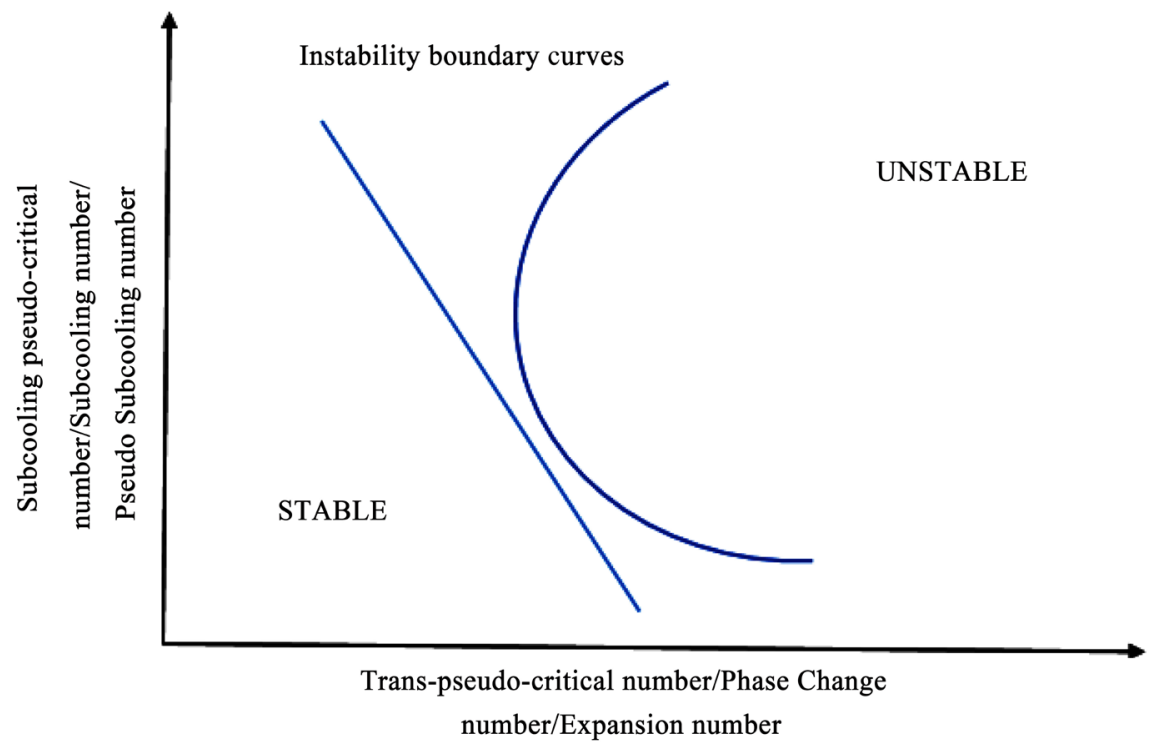

Figure 2. Dimensionless stability diagram for describing flow instability of a system. 


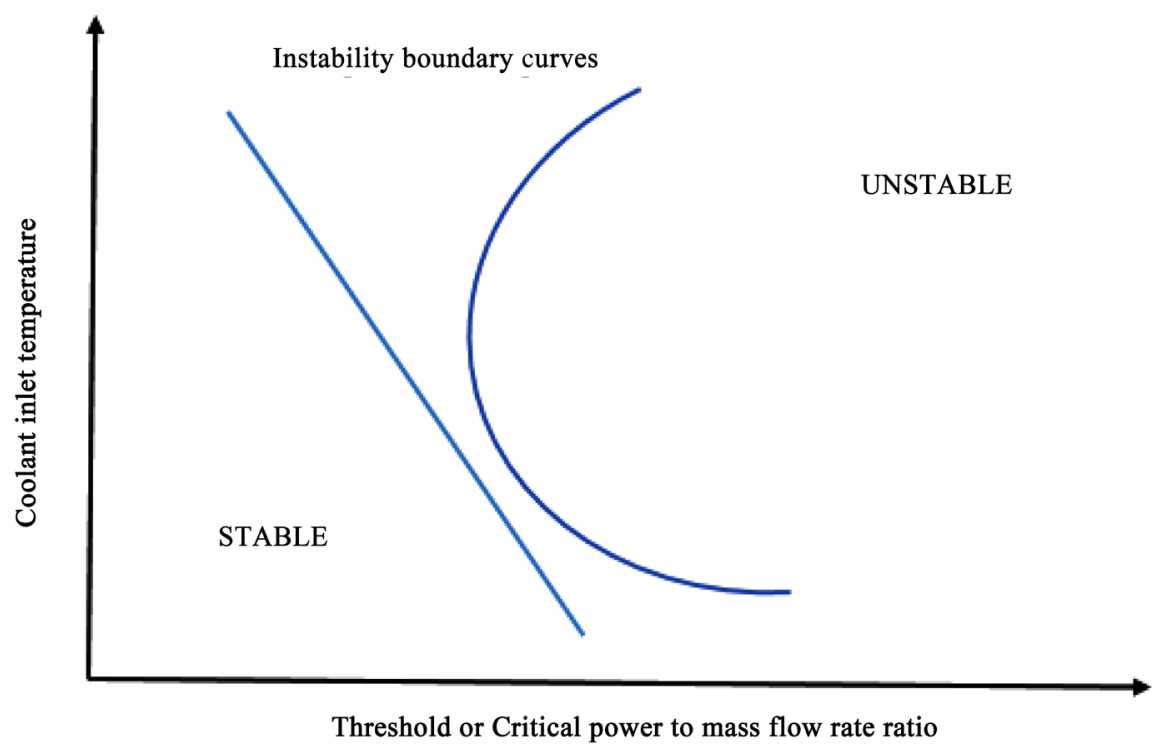

Figure 3. Dimensional stability diagram for describing flow instability of a system.

conditions to the right of the instability boundary curves are referred to as "Unstable region" to operate a system. The trends of flow instability results obtained and described in stability diagrams are almost linear or curves in most cases.

Figures 4(a)-(c) respectively show Schematic diagram of a parallel-channel test facility, Inconnel 625 pipe in the experiment and Experimental channels/ pipes in the test section of the flow instability experiment carried out by Xi et al. [11]. Similar parallel-channel experimental set-ups were adopted by Xiong et al. [15] and Zhang et al. [14] for their flow instability experiments. Detailed description of the experiments can be found in the literatures: Xi et al. [11], Xiong et al. [15], and Zhang et al. [14]. The main effect of parallel channel on fluid flow and heat transfer with heating power beyond the threshold or critical power of flow instability is the occurrence of out of phase mass flow rate oscillations in the parallel channels. As flow oscillations develop in the parallel channels with heating power beyond critical power, it is no more possible to maintain symmetrical distribution of flow rate in the parallel channels due to disturbance caused by the power increment beyond the critical power and hence the occurrence of out of phase mass flow oscillations. For single channels, the occurrence of the mass flow oscillations comes about as a result of perturbation of the flow at an initial stable steady state. If the perturbation grows with time, the corresponding operating condition is assumed to be unstable leading to sustained mass flow oscillations. If the perturbation dies down then the corresponding operating condition is assumed to be stable [33].

Investigation of flow instability can be carried out by three different approaches including theoretical analysis with frequency domain method (FDM); time domain method (TDM) with one dimensional (1D) and three dimensional (3D) codes; and by experiment. Because of the high temperature and pressure conditions that are associated with experiments at supercritical pressures, there 


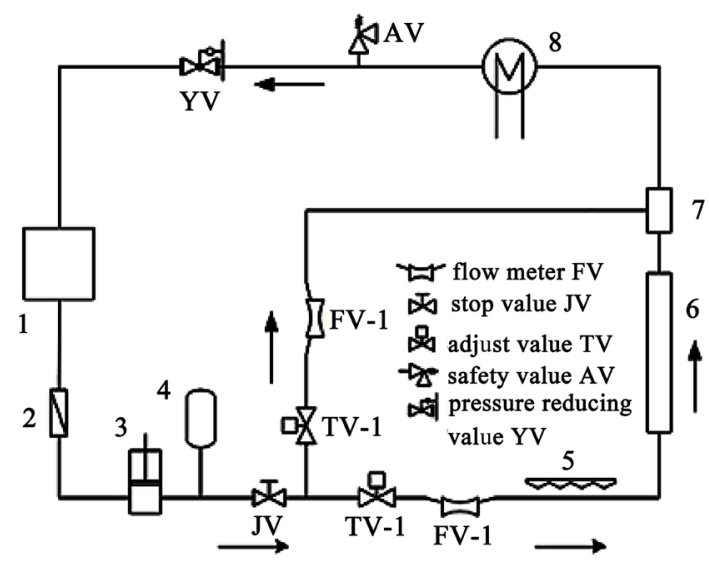

1. water tank 2. filter 3. plunger pump 4. accumulator 5. pre-heater 6. test section 7. mixing plenum 8 . heat-exchanger (a)

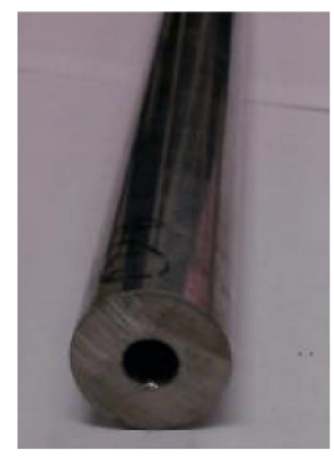

(b)

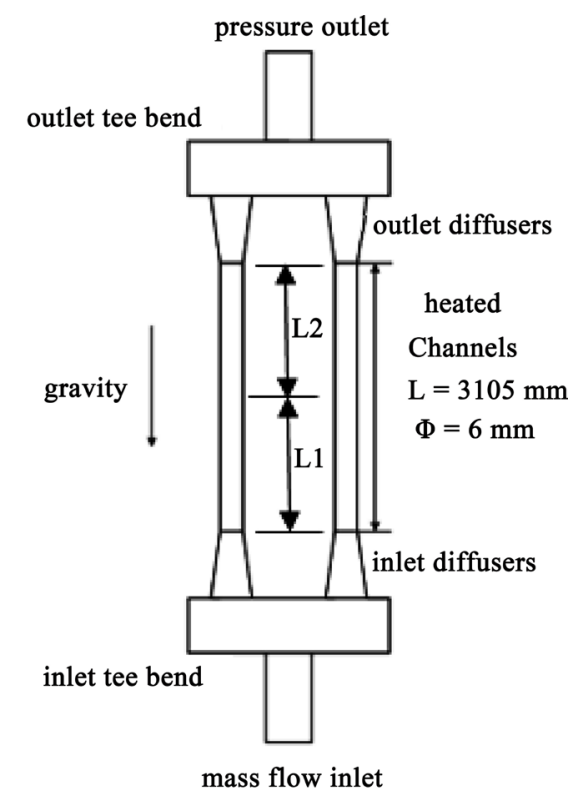

L1 heated inlet section

L2 heated outlet section

(c)

Figure 4. The schematic diagram of test facility (a), INCONEL 625 pipe in experiment (b), and Experimental channels/pipes in the test section (c) [33].

are few supercritical flow instability experiments for flow instability investigations. Most of the investigations at supercritical pressures are based on FDM and TDM [11].

Frequency-domain analysis is based on the linearization of nonlinear equations by perturbing the governing equations around a steady-state point. Once the linear model has been converted from time domain to a frequency domain, exact analytical solutions can be obtained. As a result, marginal stability boundaries (MSBs) in a parameter space can be determined and the space is divided into stable and unstable regions. In order to obtain stability boundaries in Time- 
domain analysis, the nonlinear time domain approach relies on a digital numerical simulation of nonlinear partial differential equations (PDEs) by means of finitedifference techniques [34].

Koshizuka et al.; Yi et al.; Jain and Corradini; and Zhao et al. performed various studies analyzing flow instability in the SCWR based on FDM. Their findings include flow instability will not occur if the inlet pressure loss coefficient is big enough; SCWR will be stable when operated under normal operation condition, but could be unstable when operated under low power condition such as start-up phase; flow instability is obtained in natural circulation loops; specific heat capacity of fuel rod and existence of water rod will favor the stability of SCWR; and parameters such as core height, axial power shape, inlet mass flow rate and density feedback have less influence on flow instability [11].

There are several research activities that were carried out addressing flow instability at supercritical pressures using time domain method (TDM) with one dimensional (1D) and/or three dimensional (3D or CFD) codes. In most commercial CFD codes, CFD approach adopts the fundamental governing conservation equations and these equations are solved using Finite Volume method whilst system codes (ID codes) adopt the lump parameter approach [33]. Ambrosini [7], Ampomah-Amoako [8], and Ampomah-Amoako and Ambrosini [35] reported that there is a basic continuity between the static Ledinegg instability and the dynamic density-wave oscillation. In fact, in order to examine the capability of CFD models in predicting purely thermal-hydraulic instability phenomena, Ampomah-Amoako and Ambrosini [35] adopted CFD code for flow instability investigation in circular channels and fuel bundle slices without considering the effects of heating structures and as a basis, compared the marginal stability boundary obtained by transient calculations with those obtained by in-house $1 \mathrm{D}$ code. They noted that further study is needed to analyze the effects of heat transfer deterioration and spacer grids on stability of the SCWR for the final design of a future SCWR core. On the other hand, Ambrosini [7] employed three different analysis tools, including a system code and in-house linear and transient analysis programs, and analyzed marginal stability boundaries obtained at different channel throttling conditions and orientations. Debrah et al. [36] reported that a perturbation amplification factor which is used for a quantitative evaluation of natural circulation loop stability, depends on the dimensionless power-to-flow ratio and the dimensionless heater inlet enthalpy, and also confirmed that decrease in heat transfer coefficient leads to occurrence of unstable behavior, indicating that other closure laws be implemented in the code to enable accurate prediction of heat transfer and flow instability. Debrah et al. actually used a system code and an in-house code written in dimensionless form for the stability analysis and as a basis, compared the results with an existing experimental data. Debrah et al. [37] mentioned that numerical models equipped with heat transfer and friction correlations could not satisfactorily predict supercritical instabilities, and there is the need to examine different contributing 
factors that challenge the capability to obtain accurate predictions. These contributing factors include: consideration of better closure laws for key phenomena including heat transfer and friction; a thorough knowledge of geometrical details necessary to design geometrical model for flow instability numerical simulations; truncation error effects that influence oscillation amplitude; and accurate prediction of heat losses.

Dutta et al. [38] [39] used 1-D thermal-hydraulic model, THRUST, to simulate and analyze the CANDU supercritical water reactor (SCWR) from the thermodynamic point of view without taking into consideration the neutronic coupling effect in an attempt to determine the conditions for occurrence of density wave oscillations. Based on the marginal stability boundaries obtained, the influence of various parameters including operating pressure, mass flow rate, local pressure drop coefficient, axial heat flux profile, and friction factor on the marginal stability boundaries of the reactor were analyzed. Ebrahimnia et al. [40] adopted CFD code ANSYS CFX v14.5 to analyze static and oscillatory flow instabilities in a vertical pipe of SCW flowing upward using the standard k- $\varepsilon$ model with a scalable wall-function and the $\mathrm{k}-\omega$-based SST model. The marginal stability boundary results of the CFD code were compared with the predictions of 1-D non-linear code. They observed that there were no significance difference in the marginal stability boundary results obtained using the k- $\varepsilon$ and the SST models. Because of the differences in the pressure drop predictions by the two different codes, there were significant differences between the results of the CFD and 1-D codes obtained.

Several types of studies have been made to understand and address flow instability at supercritical pressures by considering four structure types of the studied fluids. These types of investigations include studies involving single-channel stabilities, parallel-channel stabilities, reactor core flow instabilities and natural circulation or closed-loop system stabilities [41]. Rahman et al. [42] reviewed studies on supercritical water heat transfer with the aim of providing references for SCWR researchers. It was found out that most of the CFD studies and experimental studies were performed with single tube geometry due to the complexity of parallel channel geometry. Because of studies performed with parallel channel geometry could provide detailed information to the design of the SCWR core, they called for more studies in parallel channel geometry at supercritical pressures in the future. This review focused mainly on studies involving parallelchannel stabilities at supercritical pressures.

\section{Numerical Studies Addressing Flow Instability in Parallel Channels}

Hou et al. [30] studied the dynamic stability characteristics of the fast-spectrum zone of a newly designed mixed-spectrum SCWR (SCWR-M), which is characterized as a parallel-channel system. They performed linear stability analysis using a frequency-domain model developed. They observed that the normal opera- 
tion condition is within the stable region based on the Marginal stability boundaries MSBs obtained under several conditions for the parallel-channel system. The following conclusions: the hottest channel with the lower power density is more stable (the more assemblies the hottest region consists of, the lower the averaged power density of the region) (Figure 5), the system stability increases with mass flow rate (Figure 6) and systems with uniformly axial power distribution are more unstable than those with cosine-shaped or fork/stair-shaped axial power distributions (Figure 7), were achieved based on the linear stability analysis.

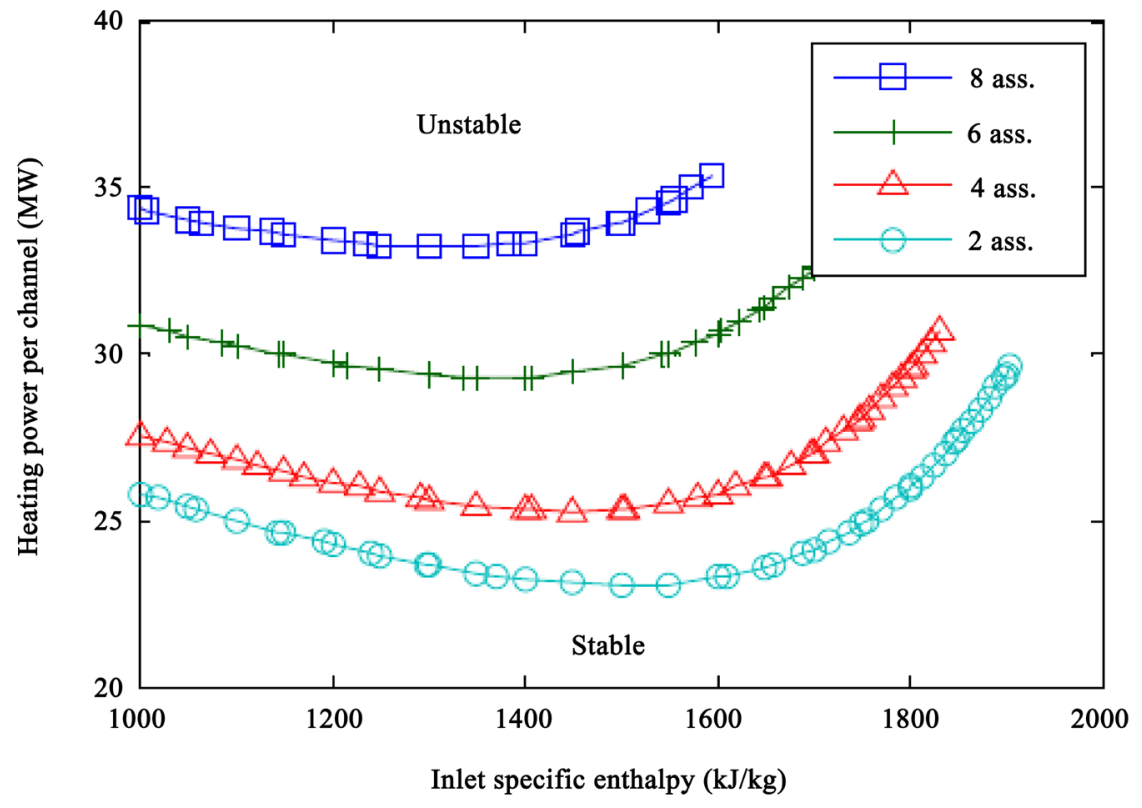

Figure 5. Stability boundaries of twin-channel systems with different subdivision schemes [30].

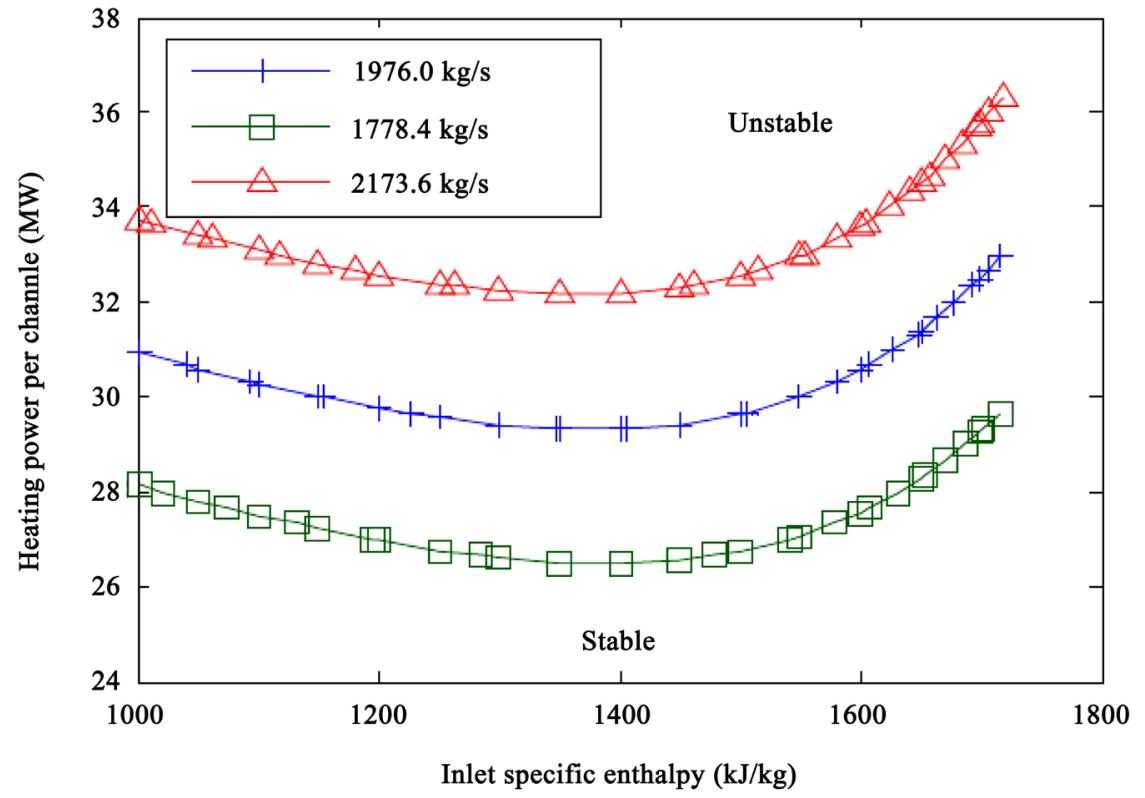

Figure 6. Stability boundaries for systems with different mass flows [30]. 


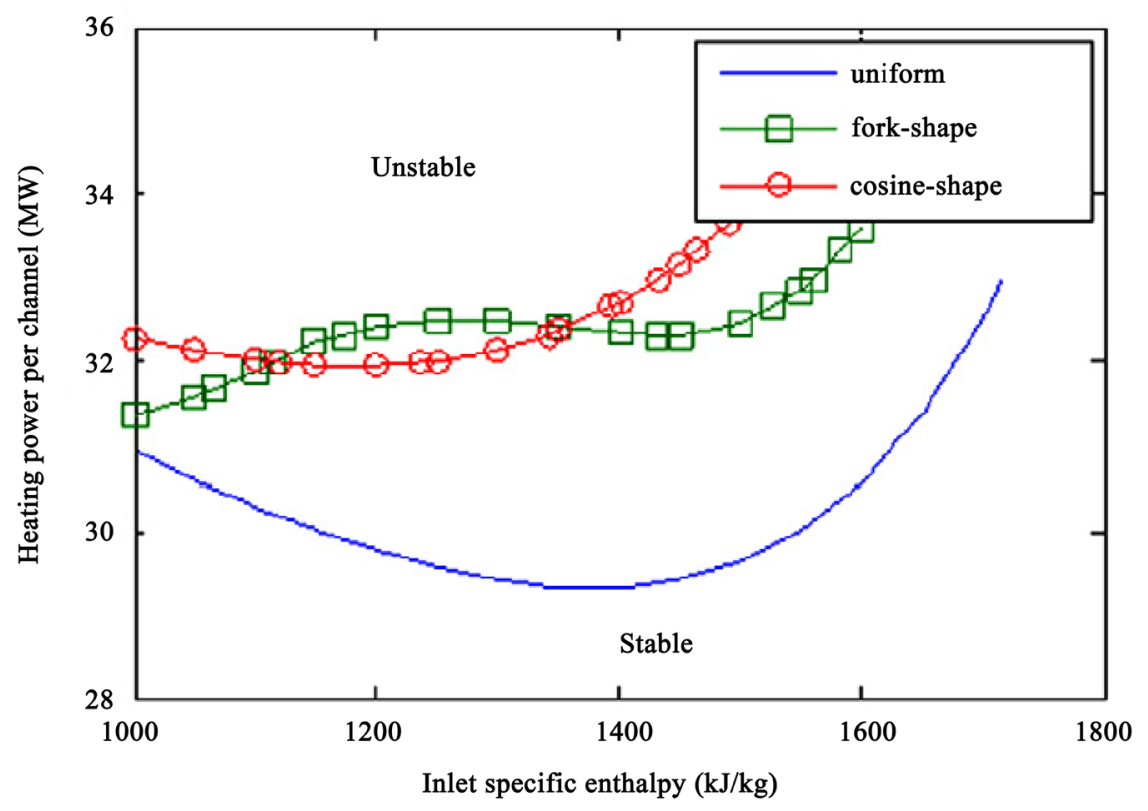

Figure 7. Stability boundaries for systems with different axial power distributions [30].

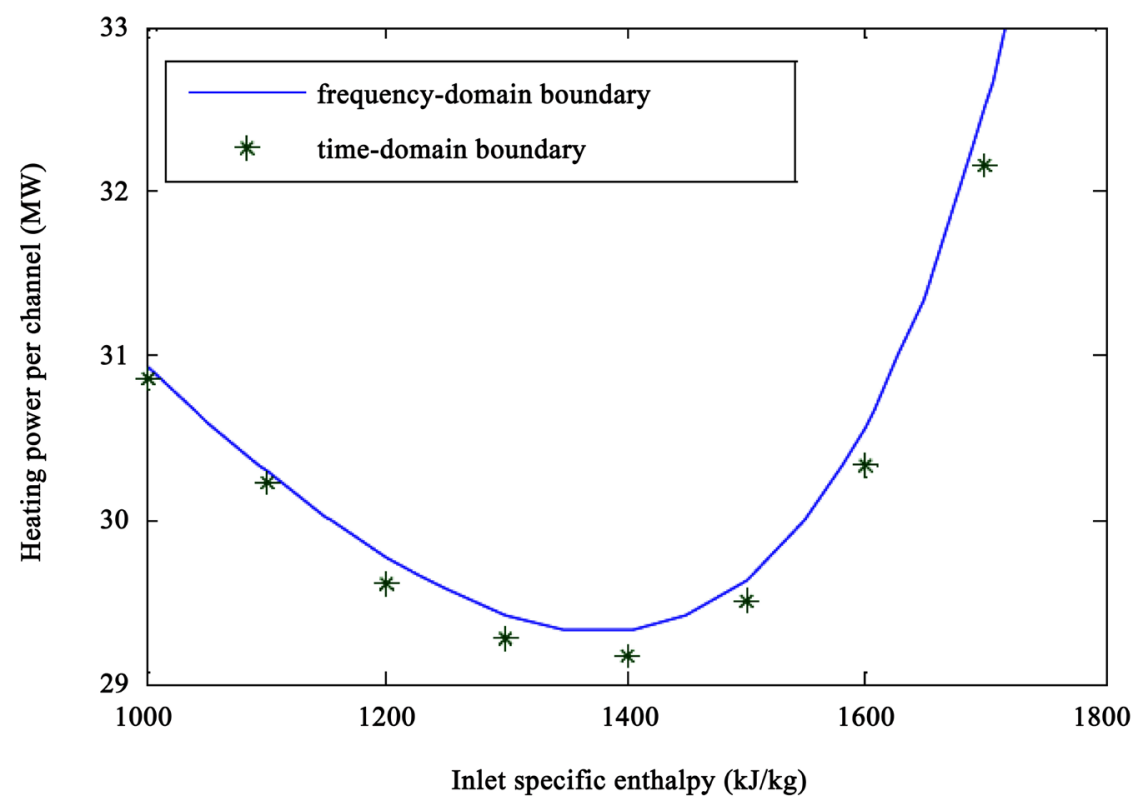

Figure 8. The stability boundaries comparison between frequency-domain and time domain calculations [30].

A single-phase one-dimensional model in the time domain was developed also for non-linear analysis. The results of the non-linear analysis agree quite well with that of frequency-domain analyses (Figure 8).

Xiong et al. [32] developed an in-house code to investigate supercritical flow instability in parallel channels. The numerical code predicted quite well the stability boundaries in comparison with the experimental data (Figure 9). It can also be observed in Figure 9 that the numerical code under-predicted the experimental data considered. They observed that the entrance and riser sections are 
important to numerical modeling of flow instability in parallel channels and cannot be eliminated (Figure 10). According to Xiong et al., the deviation of Model $\mathrm{C}$ confirms the speculation that the entrance and riser sections are important to numerical modeling of flow instability in parallel channels and cannot be eliminated. The entrance and riser sections have been eliminated in geometrical

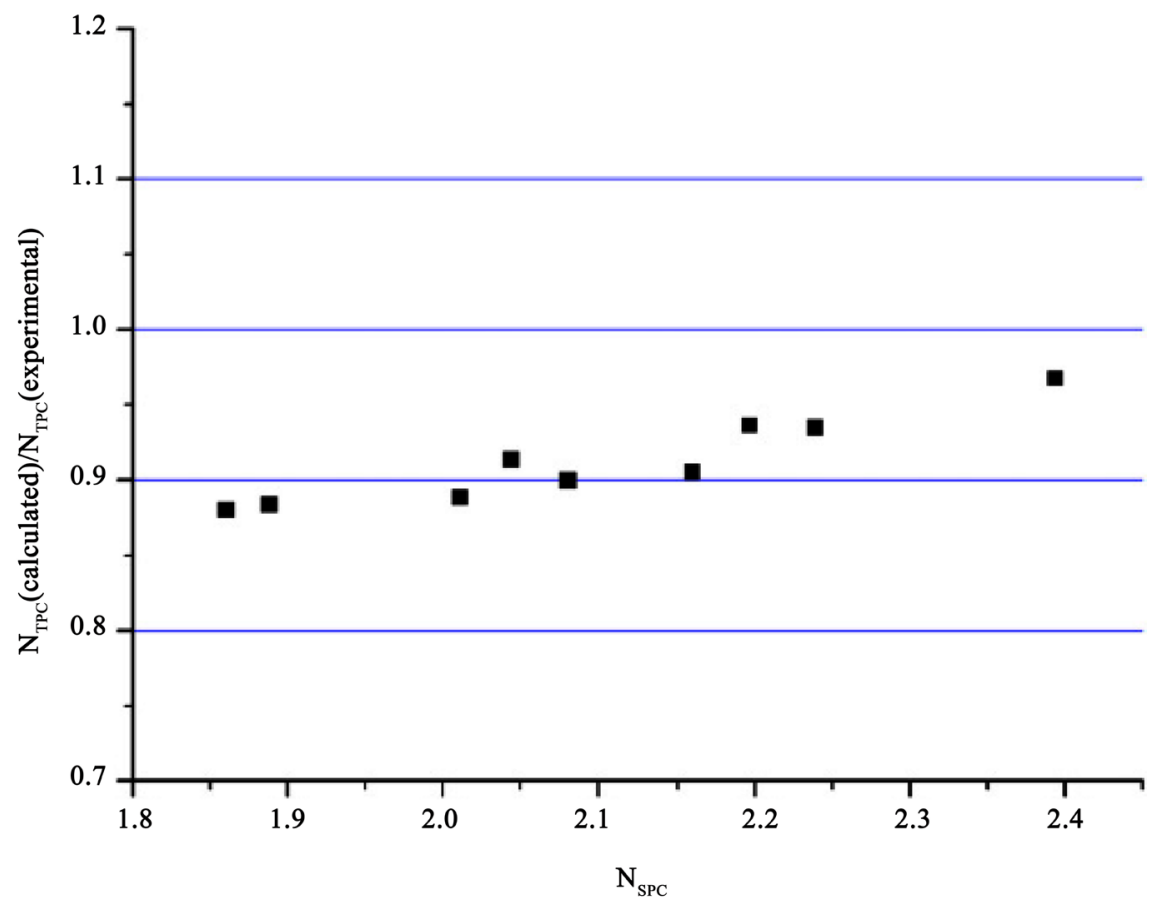

Figure 9. Comparison between the calculated and experimental results [32].

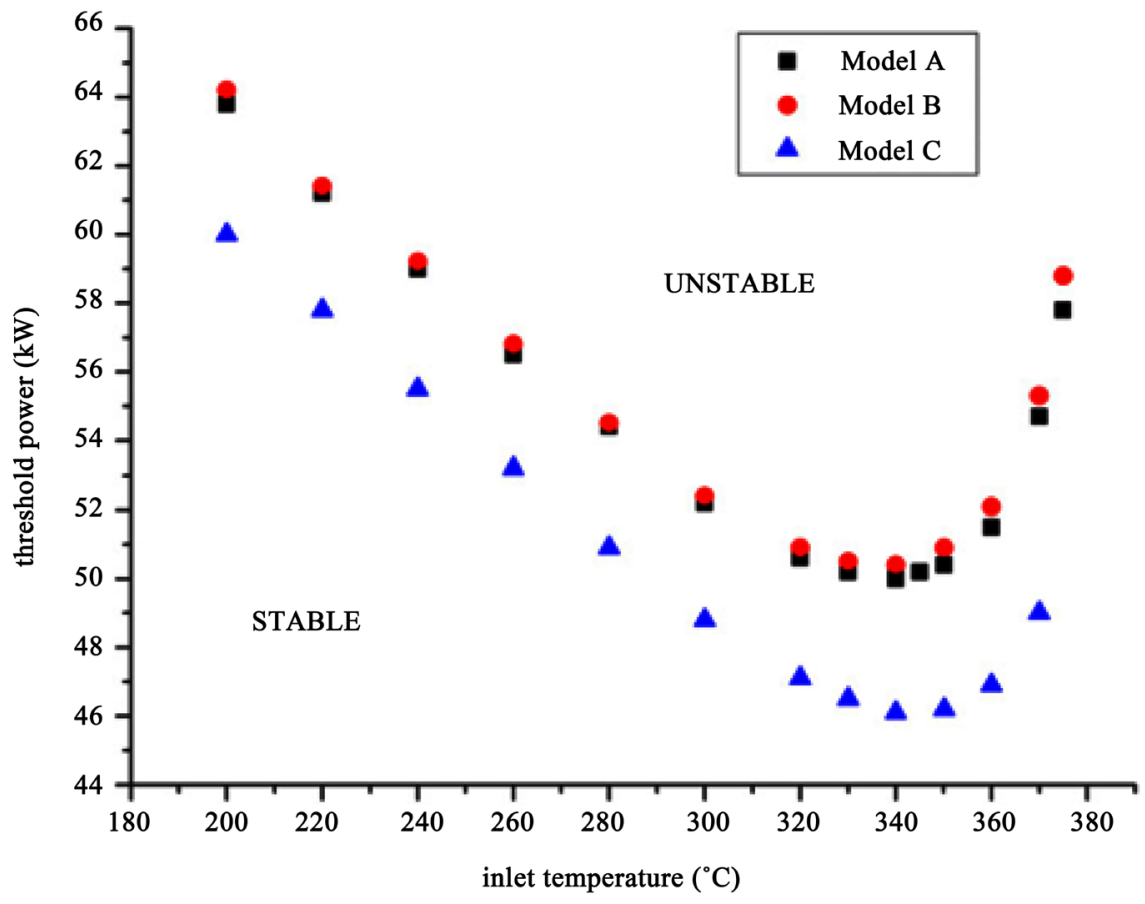

Figure 10. Comparison of boundaries between the geometrical models [32]. 
modeling of model C. They observed also that the variation of inlet temperature with the threshold power is not linear and the threshold power is more or less proportional to the total mass flow rate irrespective of whether the flow distribution in the parallel channels is symmetrical or not (Figure 11 and Figure 12).

$\mathrm{Su}$ et al. [31] performed theoretical study on flow instability of supercritical water in the parallel channels using tiny perturbation method. The marginal stability boundary (MSB) was obtained by using dimensionless numbers, $\mathrm{N}_{\mathrm{SPC}}$ (Pseudo-subcooling number) and $\mathrm{N}_{\mathrm{TPC}}$ (pseudo-phase change number) and

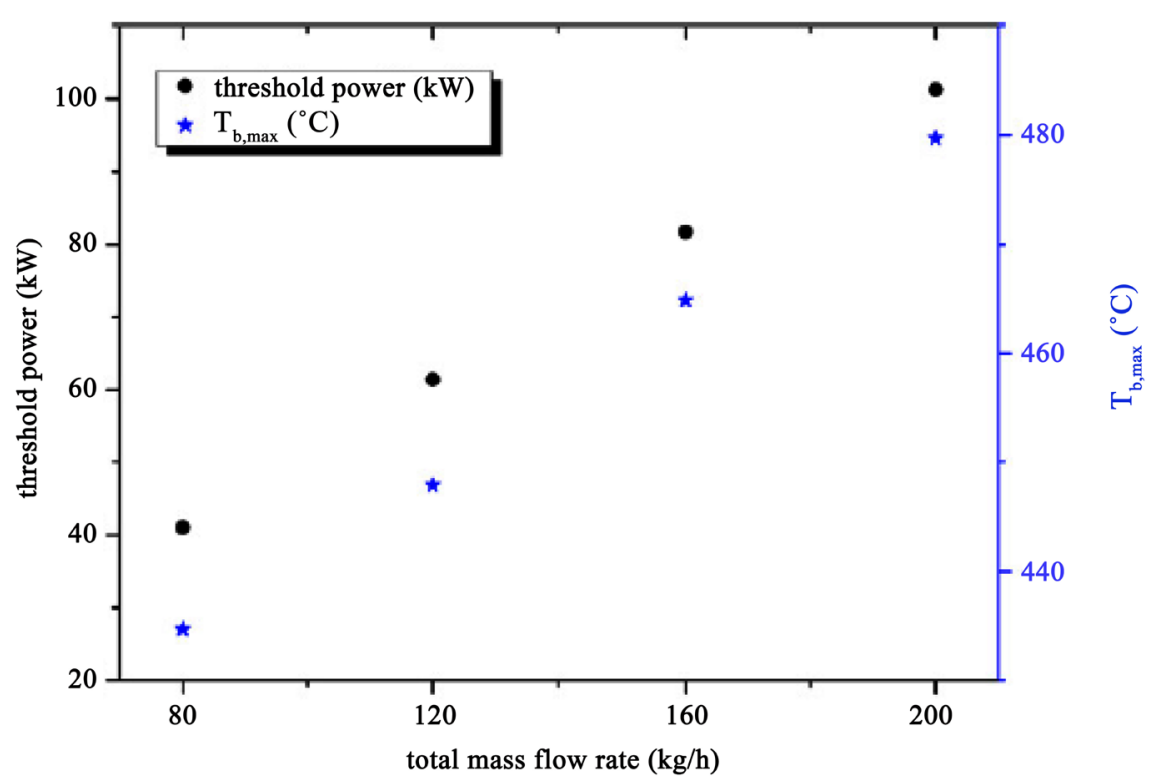

Figure 11. Effect of total flow rate on the threshold power and outlet temperature (asymmetrical) [32].

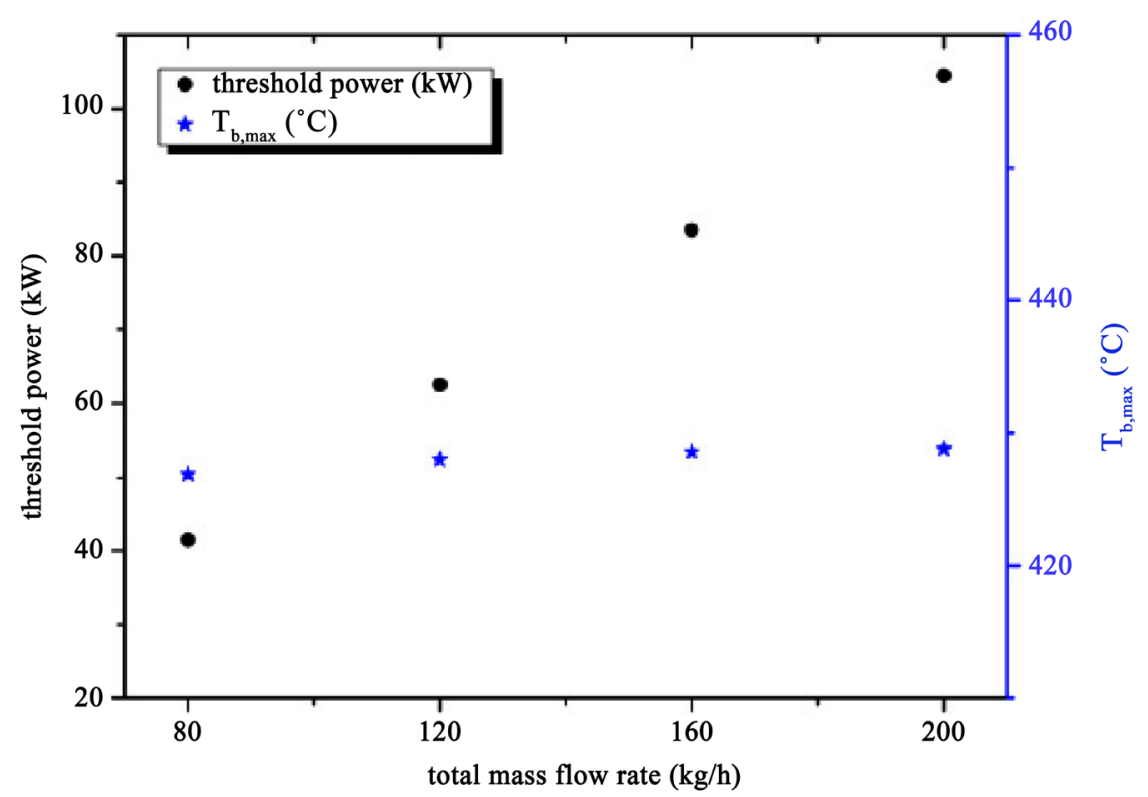

Figure 12. Effect of total flow rate on the threshold power and outlet temperature (symmetrical) [32]. 
dimensional numbers, heat flux and mass flow rate or inlet temperature. Their parametric investigations show that the system stability increases with increasing pressure (Figure 13), increasing mass flow rate (Figure 14) and increasing frictional pressure drop (Figure 15). Figure 13 also shows that there is an inflection point corresponding to particular heat flux and inlet temperature below which stability decreases and above which stability increases with increasing inlet temperature. Their study results also show that the effect of inlet temperature in the low subcooling pseudo-critical number region is different from that in high

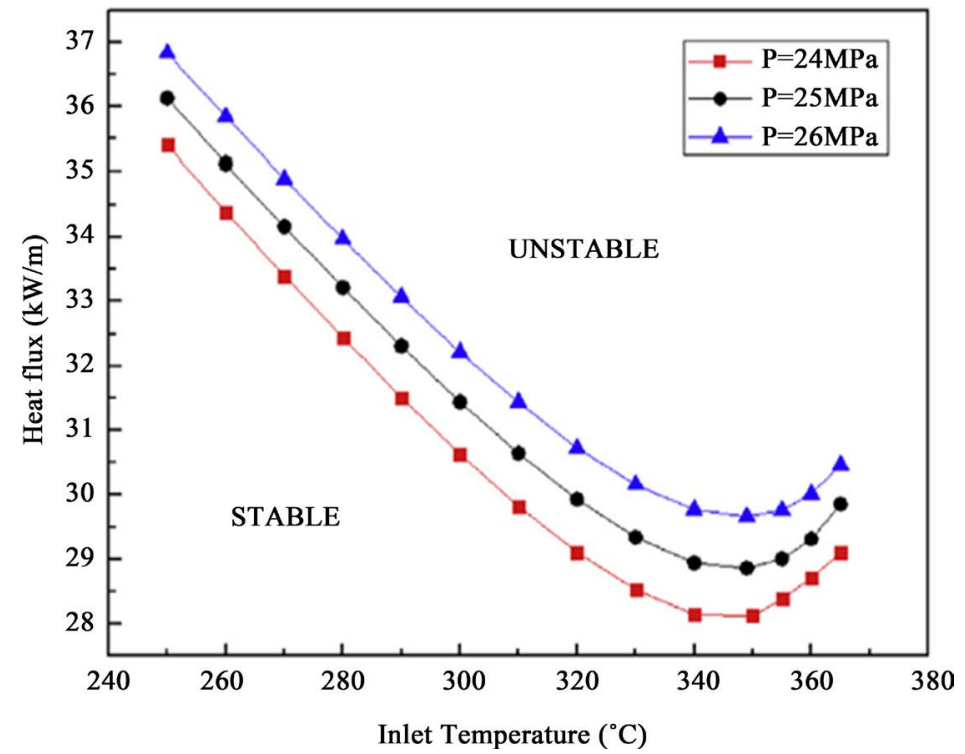

Figure 13. Effect of system pressure on the heat flux ( $\left.W_{\text {in }}=0.1 \mathrm{~kg} / \mathrm{s}, D=12 \mathrm{~mm}\right)[31]$.

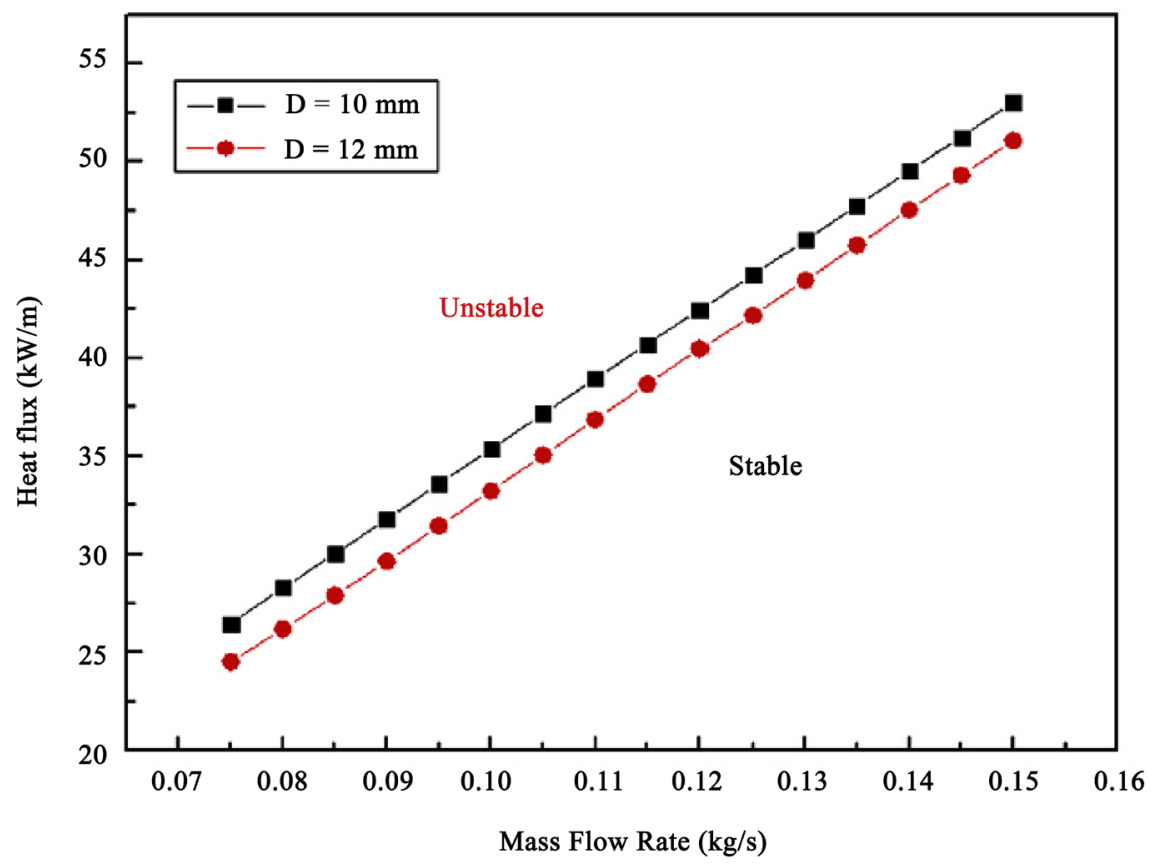

Figure 14. Effect of total inlet mass flow on heat flux associated with the critical boundary of instability with different $D\left(T_{i n}=280.0^{\circ} \mathrm{C}\right)[31]$. 


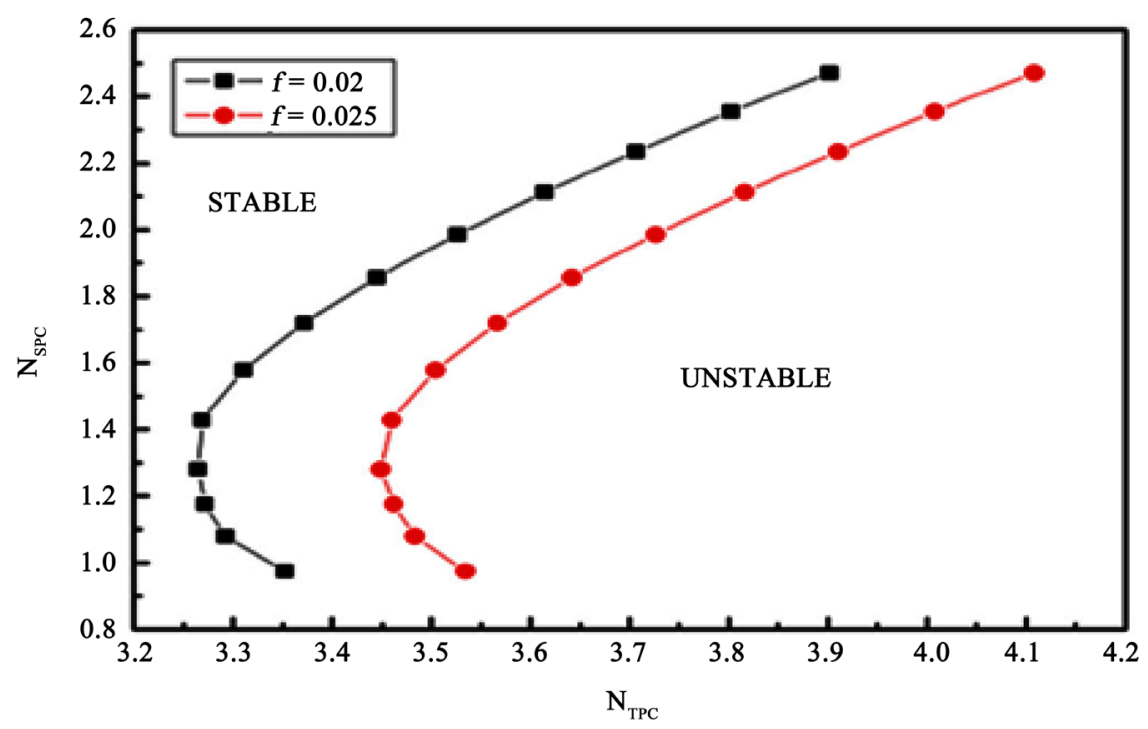

Figure 15. MSB of the system $\left(W_{i n}=0.1 \mathrm{~kg} / \mathrm{s}, D=12 \mathrm{~mm}\right)[31]$.

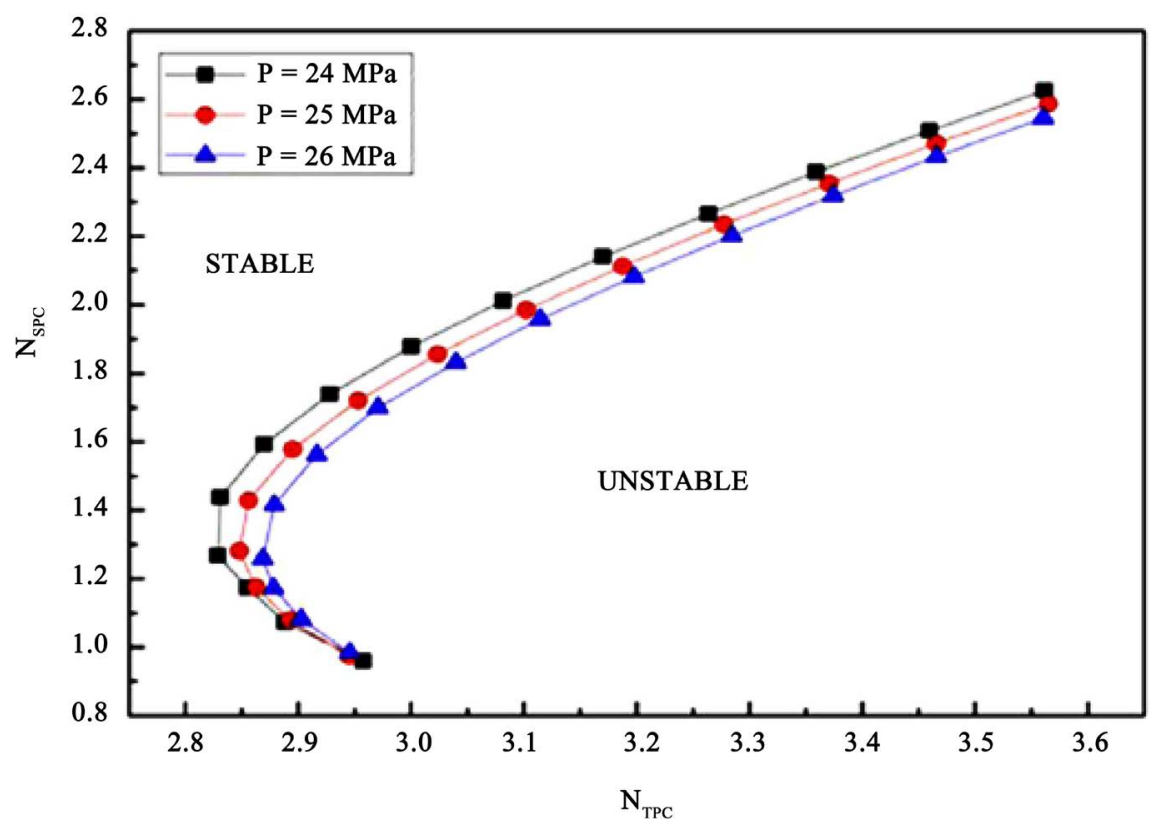

Figure 16. MSB of the system $\left(W_{i n}=0.1 \mathrm{~kg} / \mathrm{s}, D=12 \mathrm{~mm}\right)$ [31].

subcooling pseudo-critical number region, i.e., flow stability increases in the low subcooling pseudo-critical number region (high inlet temperature region) and decreases in the high subcooling pseudo-critical number region (low inlet temperature region) with increase of inlet temperature (Figure 15 and Figure 16).

Jingjing et al. [43] carried out 3-D simulation of water at supercritical pressure in parallel channels in order to investigate flow instability. It was observed that system stability increases with inlet mass flow rate (Figure 17) and the effect of inlet temperature on flow instability is not linear (Figure 18). Jingjing et al. observed also that there is particular threshold inlet temperature below which stability decreases and above which stability increases with inlet temperature (Figure 18). 


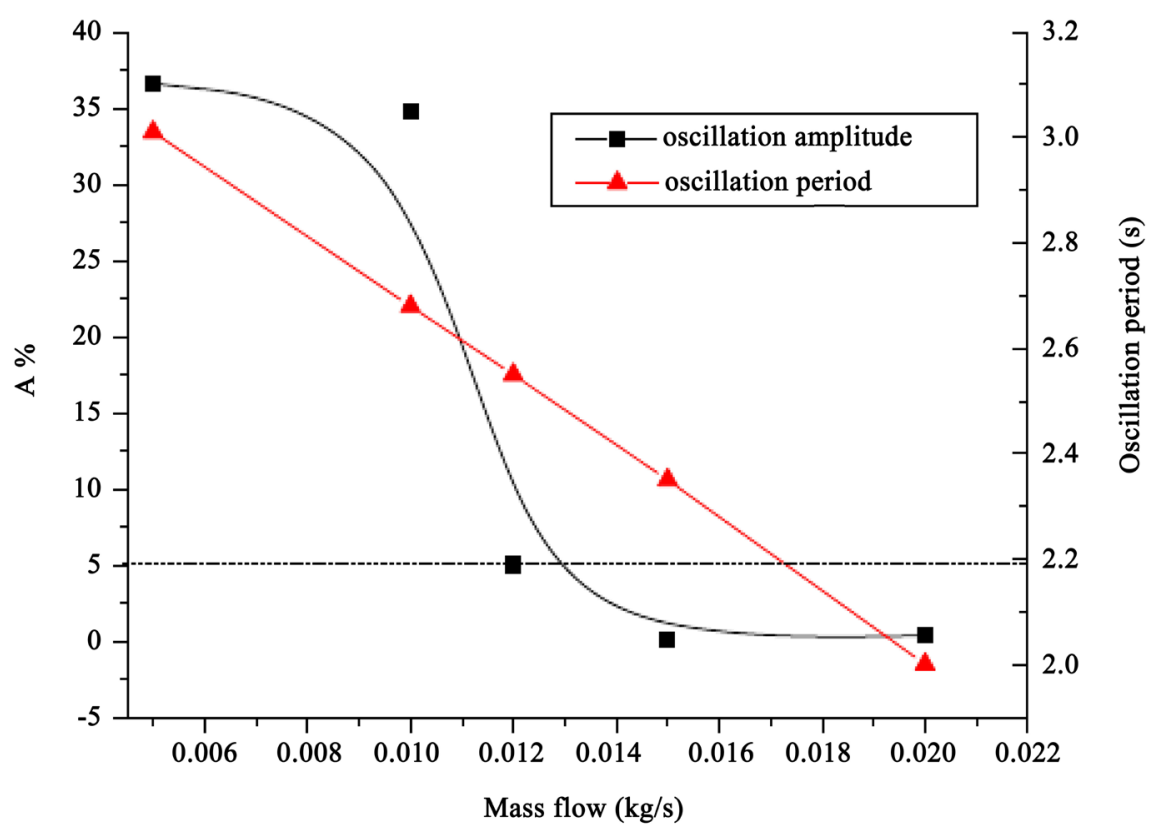

Figure 17. The influence of mass flow to flow instability [43].

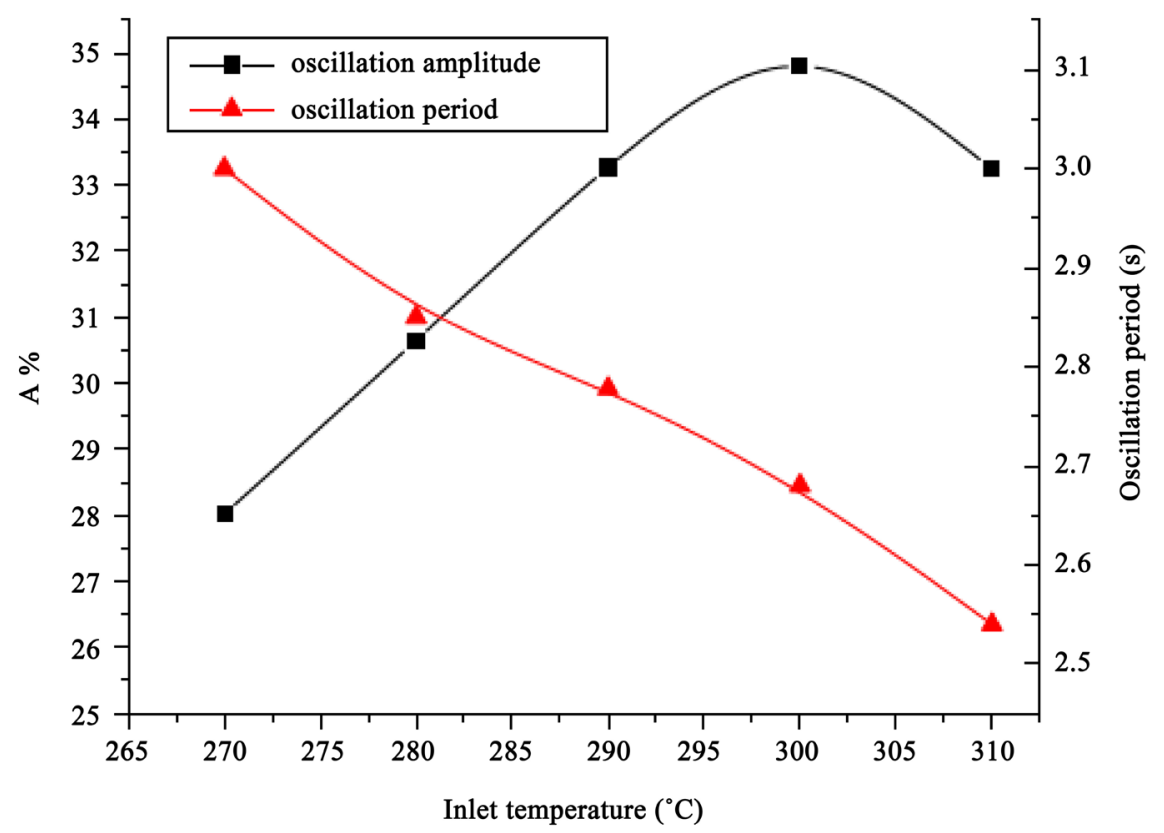

Figure 18. The influence of inlet temperature to flow instability [43].

In fact, all the above works confirmed the occurrence of instability phenomena in heated channels with supercritical fluids and much attention was paid to the 1-D dimensionless numbers adopted to describe supercritical instability boundary. There are few numerical studies, to my best of knowledge that described supercritical instability boundary using dimensional numbers, coolant inlet temperature and the ratio of critical or threshold power to mass flow rate, rather than using dimensionless numbers. These studies were performed by Xi [12] and Shitsi et al. [33] [44]. 
Xi et al. [12] made use of three dimensional (3D) CFX code and performed flow instability analysis investigating an out of phase oscillation in parallel channels with water at supercritical pressure. Results show that the $3 \mathrm{D}$ code could predict the onset of flow instability better than 1D code (Figure 19), but could not predict the period of oscillation, i.e. the 3D numerical estimation of the oscillation period is much longer than that of the experiment (Figure 20). The results of Xi et al. also show that instability of a system is influenced by mass flow rate (Figure 21), pressure (Figure 22) and gravity (Figure 23). That is, the system is less stable to operate at high mass flow rate and at high pressure. The system is more stable when operated without the influence of gravity.

Shitsi et al. [33] investigated flow instability in two parallel channels with supercritical water under different system pressures, inlet mass flow rates, inlet

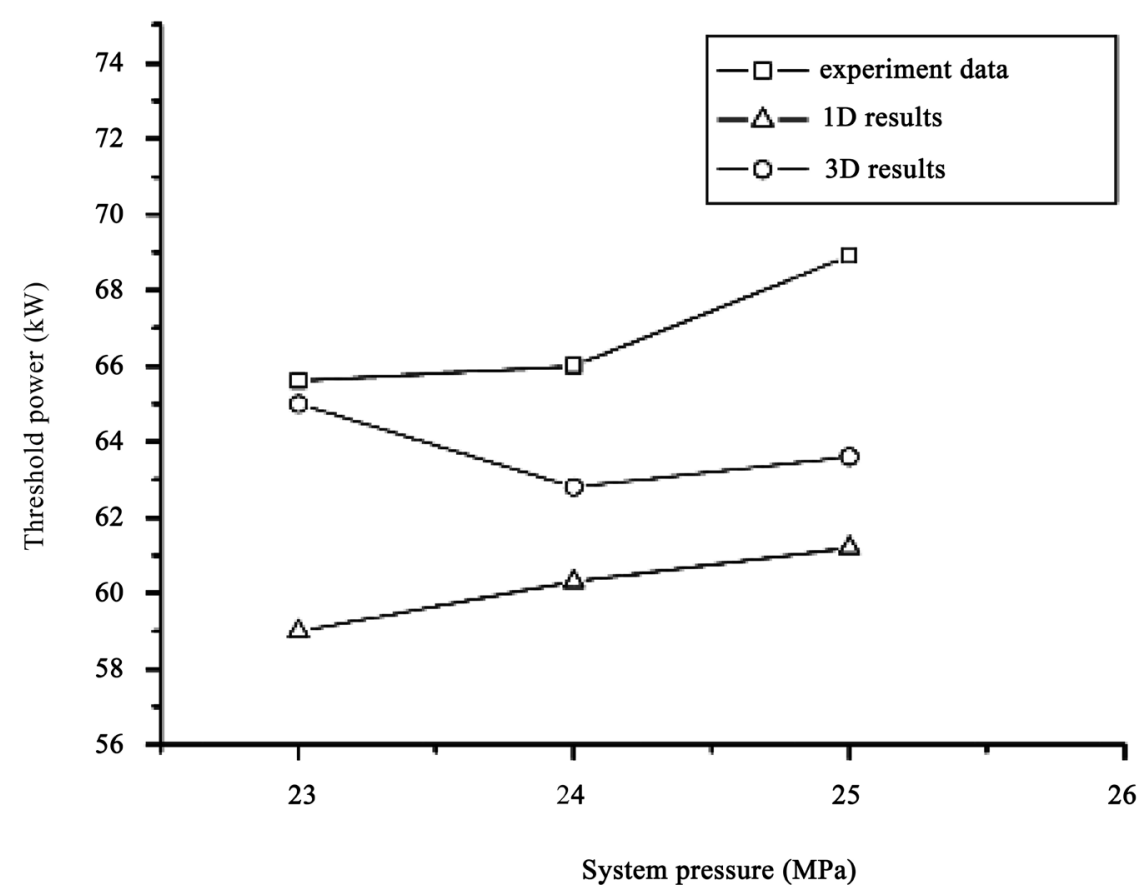

Figure 19. Influence of system pressure $\left(M_{\text {int }}=0.0333 \mathrm{~kg} / \mathrm{s}, T_{\text {int }}=220^{\circ} \mathrm{C}\right)[12]$.

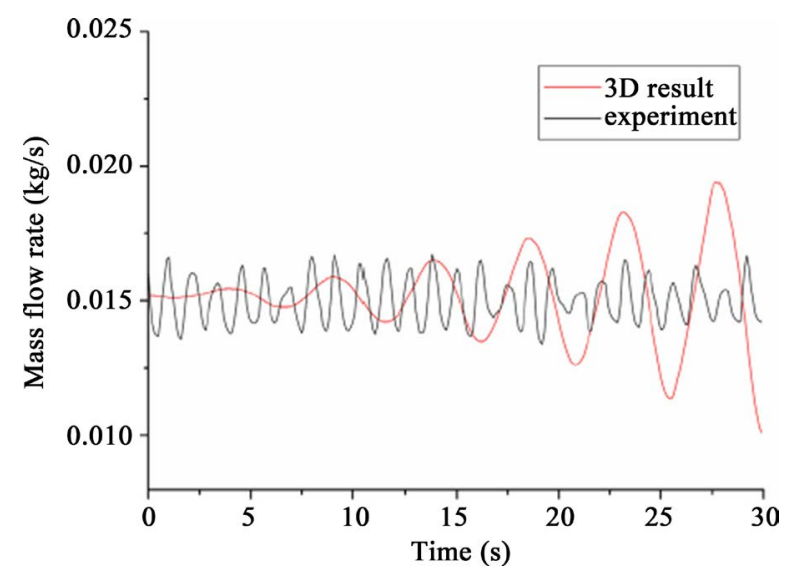

Figure 20. Oscillation of mass flow rate $M_{i n 1}$ in experiment and 3D simulation [12]. 


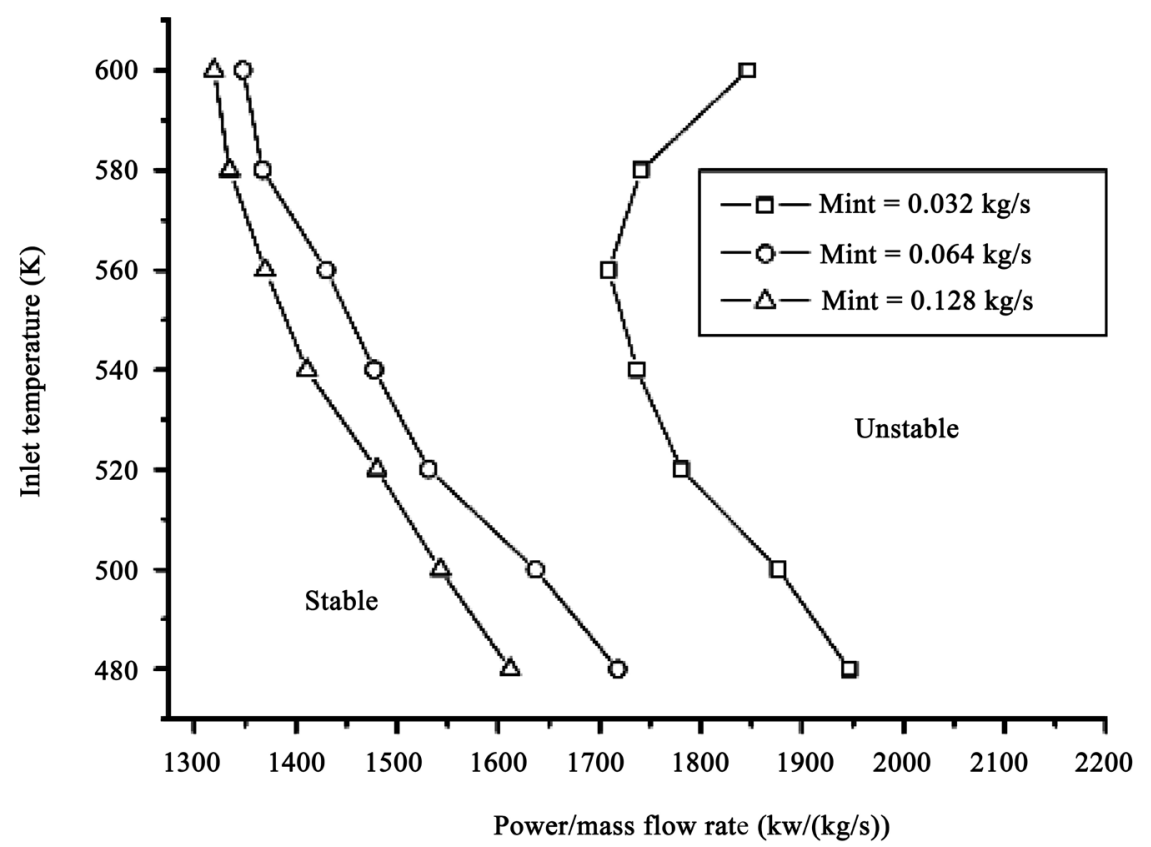

Figure 21. Instability boundaries with different total inlet mass flow rates $(P=23 \mathrm{MPa})$ [12].

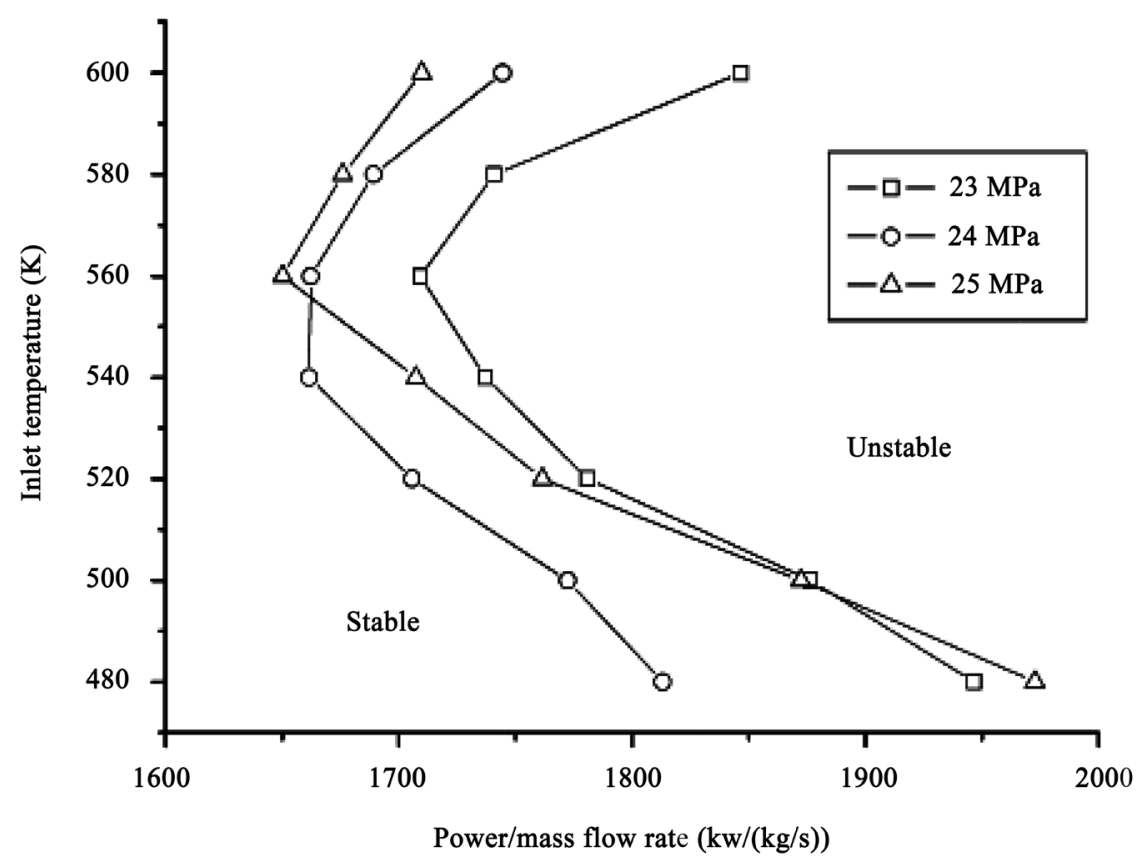

Figure 22. Instability boundaries under different system pressure $\left(M_{i n t}=0.032 \mathrm{~kg} / \mathrm{s}\right)[12]$.

temperatures and axial power shapes using STAR-CCM+CFD code. They found out that the system parameters have significant effect on the amplitude of the mass flow oscillation and maximum temperature of the heated outlet temperature oscillation but have little effect on the period of the mass flow oscillation (Tables 3-6). A system with larger amplitude of flow oscillation is more unstable. The results of Shitsi et al. and experimental data used for comparison show 


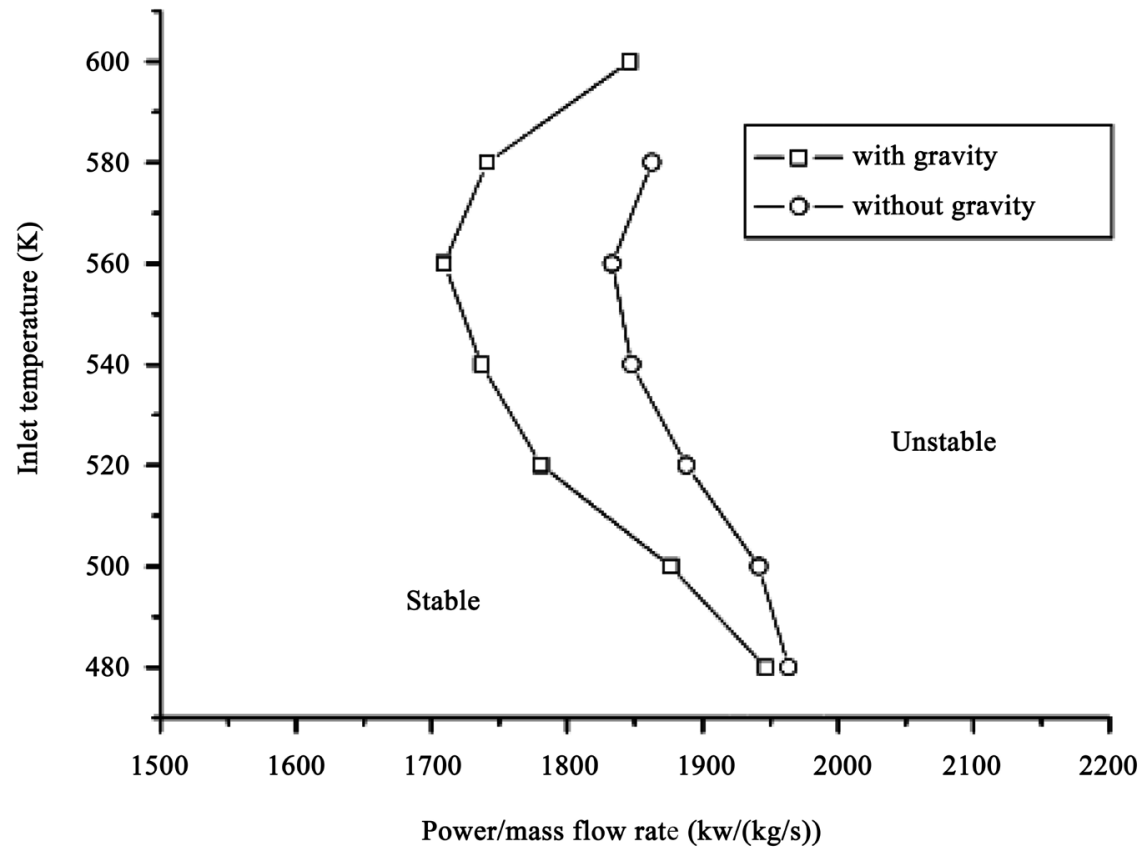

Figure 23. Instabilities boundaries with and without gravity $\left(M_{\text {int }}=0.032 \mathrm{~kg} / \mathrm{s}, P=23\right.$ $\mathrm{MPa})[12]$.

Table 3. Amplitudes and periods of oscillations for various power shapes [33].

\begin{tabular}{cccc}
\hline Power shape & Amplitude, $\mathrm{kg} / \mathrm{h}$ & Periods, $\mathrm{s}$ & Outlet temperature, ${ }^{\circ} \mathrm{C}$ \\
\hline Constant axial & 2.2 & 0.65 & 392 \\
Uniform axial & 23.0 & 0.87 & 427 \\
Axially Decreased & 9.0 & 0.83 & 404 \\
Axially Increased & 14.7 & 1.0 & 408 \\
\hline
\end{tabular}

Table 4. Amplitudes and periods of oscillations for various operating pressures [33].

\begin{tabular}{cccc}
\hline Pressure, $\mathrm{MPa}$ & Amplitude, $\mathrm{kg} / \mathrm{h}$ & Periods, $\mathrm{s}$ & Outlet temperature, ${ }^{\circ} \mathrm{C}$ \\
\hline 23 & 5.8 & 0.8 & 391 \\
25 & 5.5 & 0.7 & 405 \\
\hline
\end{tabular}

Table 5. Amplitudes and periods of oscillations for various inlet mass flow rates [33].

\begin{tabular}{cccc}
\hline Mass flow rate, $\mathrm{kg} / \mathrm{h}$ & Amplitude, $\mathrm{kg} / \mathrm{h}$ & Periods, $\mathrm{s}$ & Outlet temperature, ${ }^{\circ} \mathrm{C}$ \\
\hline 125 & 17.0 & 0.8 & 394 \\
145 & 11.8 & 1.0 & 390 \\
\hline
\end{tabular}

Table 6. Amplitudes and periods of oscillations for flow with or without gravity influence [33].

\begin{tabular}{cccc}
\hline Gravity & Amplitude, $\mathrm{kg} / \mathrm{h}$ & Periods, $\mathrm{s}$ & Outlet temperature, ${ }^{\circ} \mathrm{C}$ \\
\hline With gravity & 6.0 & 0.7 & 389 \\
Without gravity & 5.0 & 0.7 & 388 \\
\hline
\end{tabular}


that flow stability for some operating parameters decreases with coolant inlet temperature without any point of inflection. For some operating parameters, there is point of inflection below which flow instability decreases and above which stability increases with coolant inlet temperature (Figure 24 \& Figure 25). The results of Xiong et al. [32] and Xi et al. [11] [12] also show similar observations (Figure 10, Figures 21-23, Figure 28 \& Figure 29). Shitsi et al. [44] investigated effects of heating regime (axially decreased power shape ADPS and homogeneous axial power shape HAPS) on flow instability in parallel channels. For axially Decreased power shape ADPS, the heat flux applied to the inlet of the heated section is more than the heat flux applied to the outlet of the heated

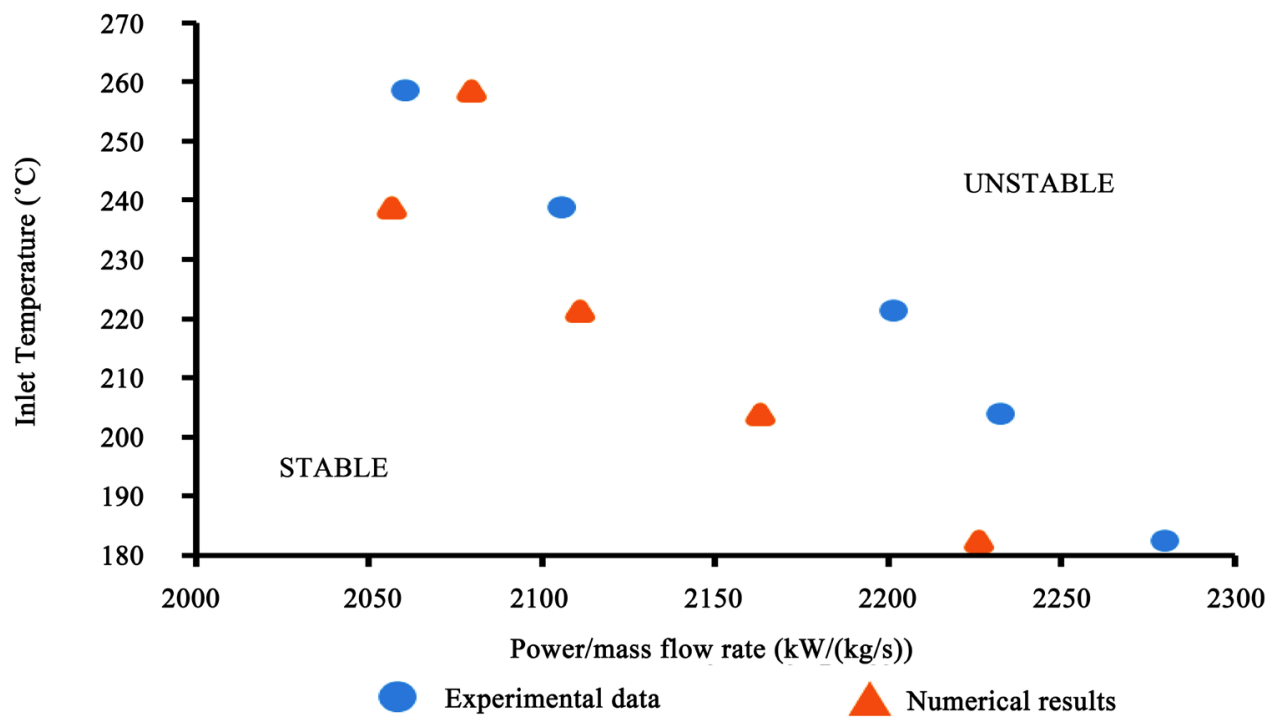

Figure 24. Instability boundary $\left(P=23 \mathrm{MPa}, M_{t}=125 \mathrm{~kg} / \mathrm{h}\right.$, homogeneous axial power distribution) [33].

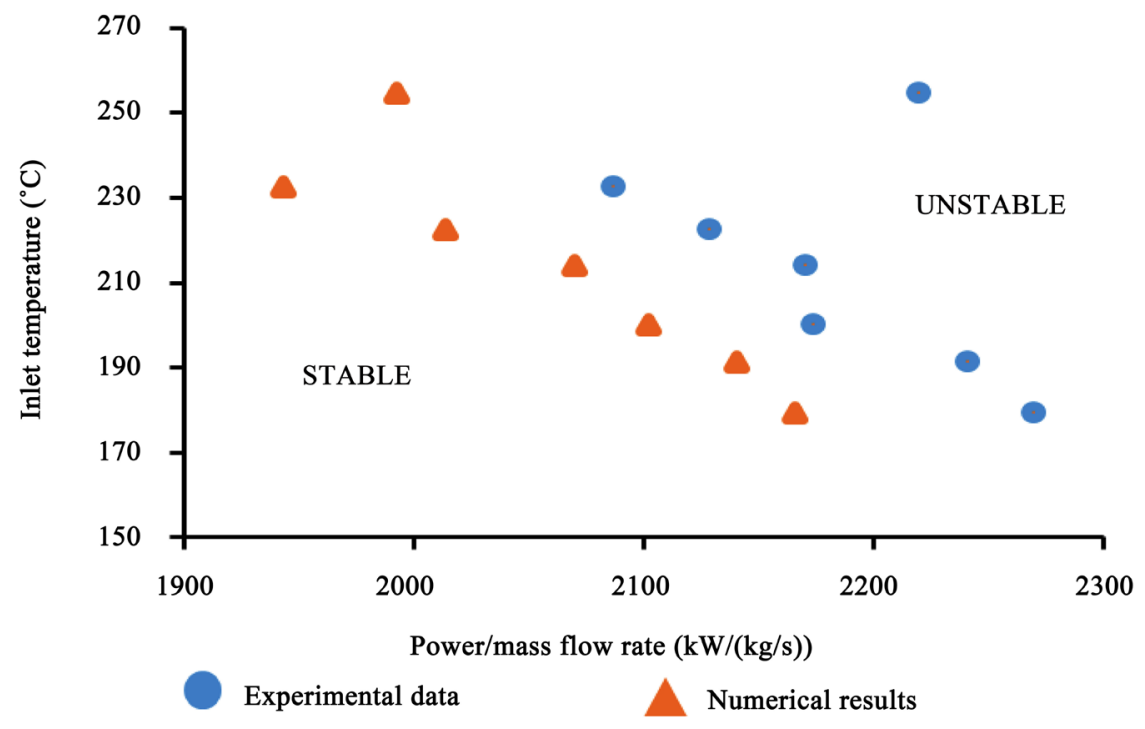

Figure 25. Instability boundary $\left(P=23 \mathrm{MPa}, M_{t}=125 \mathrm{~kg} / \mathrm{h}\right.$, axially decreased power distribution) [33]. 
section, and for homogeneous axial power shape HAPS constant heat flux is applied to the heated section. It was observed that the heating regime adopted in heating the walls of heated sections of parallel channels has significant effects on flow instability and system with HAPS is more stable than the system with ADPS.

\section{Experimental Studies Addressing Flow Instability in Parallel Channels}

To my best of knowledge, there are three experiments that were performed on flow instability in parallel channels with water at supercritical pressures. These experiments were performed by Xi et al. [11], Xiong et al. [15] and Zhang et al. [14].

Xi et al. [11] analyzed dynamics characteristics of out of phase oscillation and obtained instability boundaries under different inlet temperatures, axial power shapes, total inlet mass flow rates and system pressures. They described instability boundaries using dimensional parameters, inlet temperature and ratio of critical or threshold power to mass flow rate. They observed that flow instability is not influenced by low and high power boundaries (LPB and HPB), the same amplitude value of $25 \mathrm{~kg} / \mathrm{h}$ was obtained for mass flow oscillations at LPB and HPB (Figure 26 \& Figure 27). They indicated that system would be more stable with a uniform axial power shape at low inlet temperatures (Figure 28). Their results also show that with the increase of total inlet mass flow rate, system will become more unstable at higher power boundaries (Figure 29).

Xiong et al. [15] disregarded shot-life transient oscillations and considered

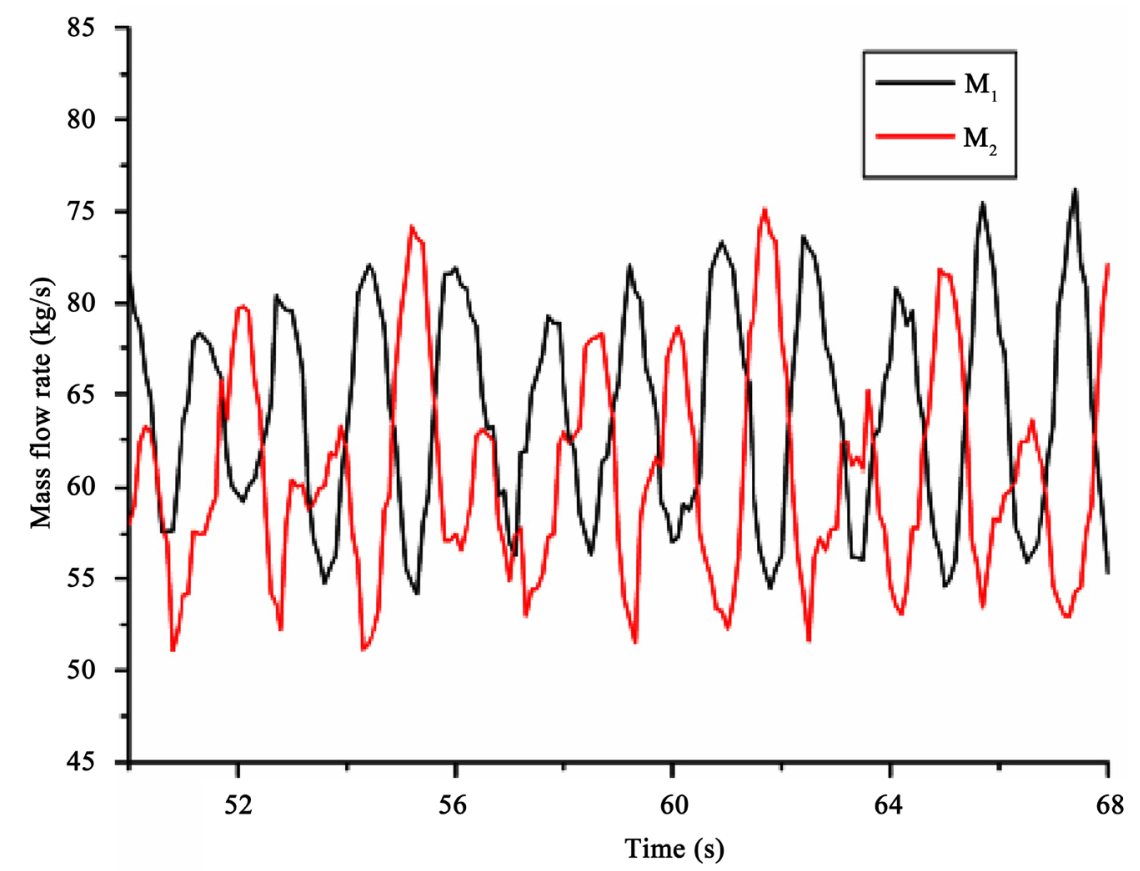

Figure 26. Inlet mass flow rate oscillation near LPB $\left(Q_{t}=55.5 \mathrm{~kW}\right.$, axial decreased power shape, $\left.T_{\text {in }}=190^{\circ} \mathrm{C}\right)[11]$. 


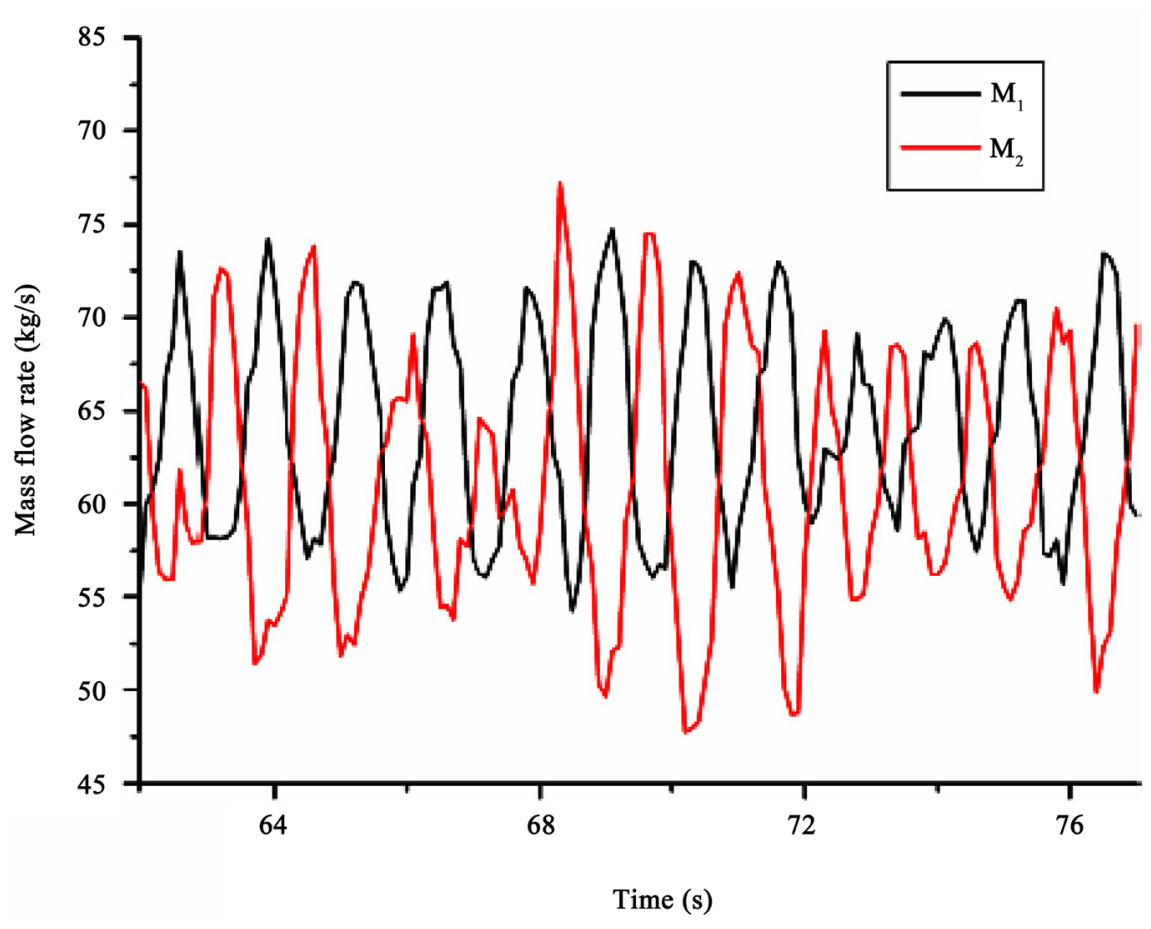

Figure 27. Inlet mass flow rate oscillation near HPB $\left(Q_{t}=81.5 \mathrm{~kW}\right.$, axial decreased power shape, $T_{\text {in }}=192^{\circ} \mathrm{C}$ ) [11].

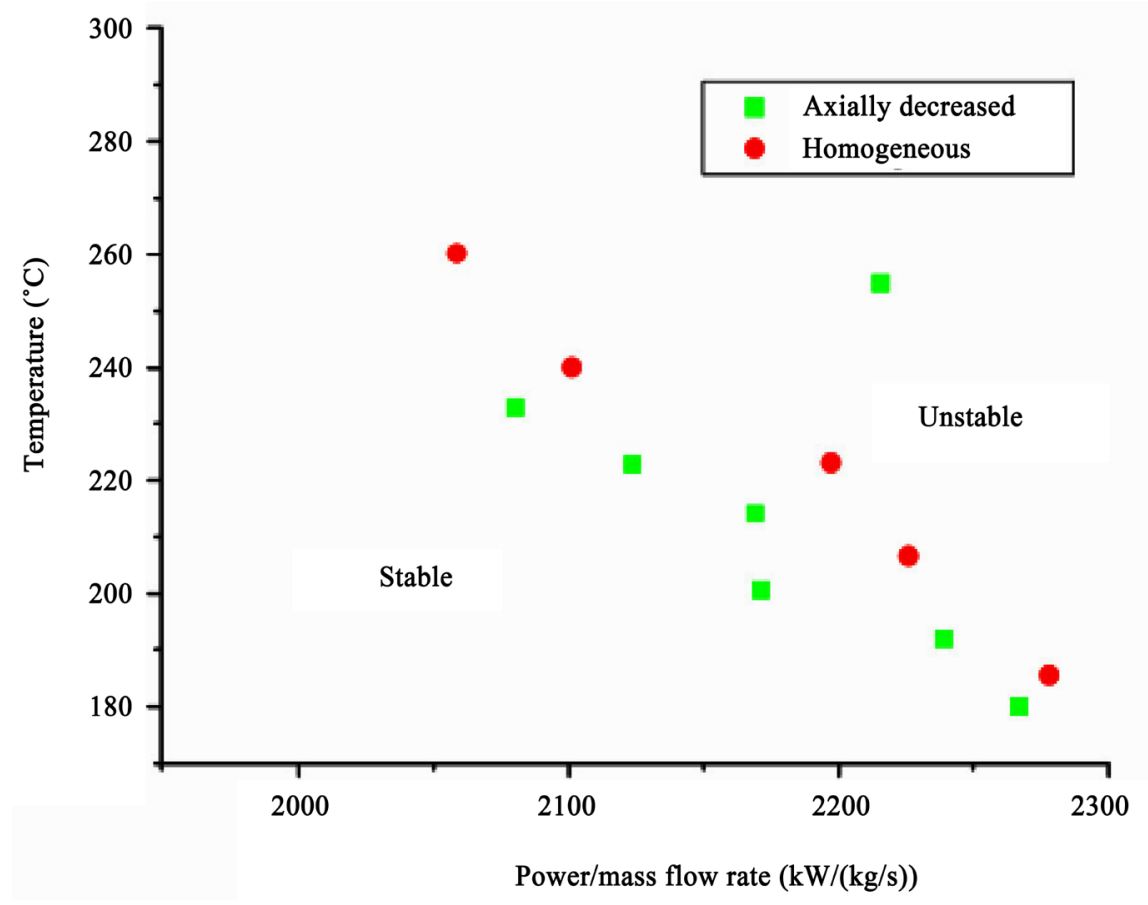

Figure 28. Influence of axial power shape on HPBs [11].

only the sustained out-of-phase oscillations accompanied by evident amplitude during the experiment. They obtained stability boundaries in a two-dimensional plane using two different approaches: two ID dimensionless parameters proposed for supercritical flow (Figure 30), and dimensional parameters such as 


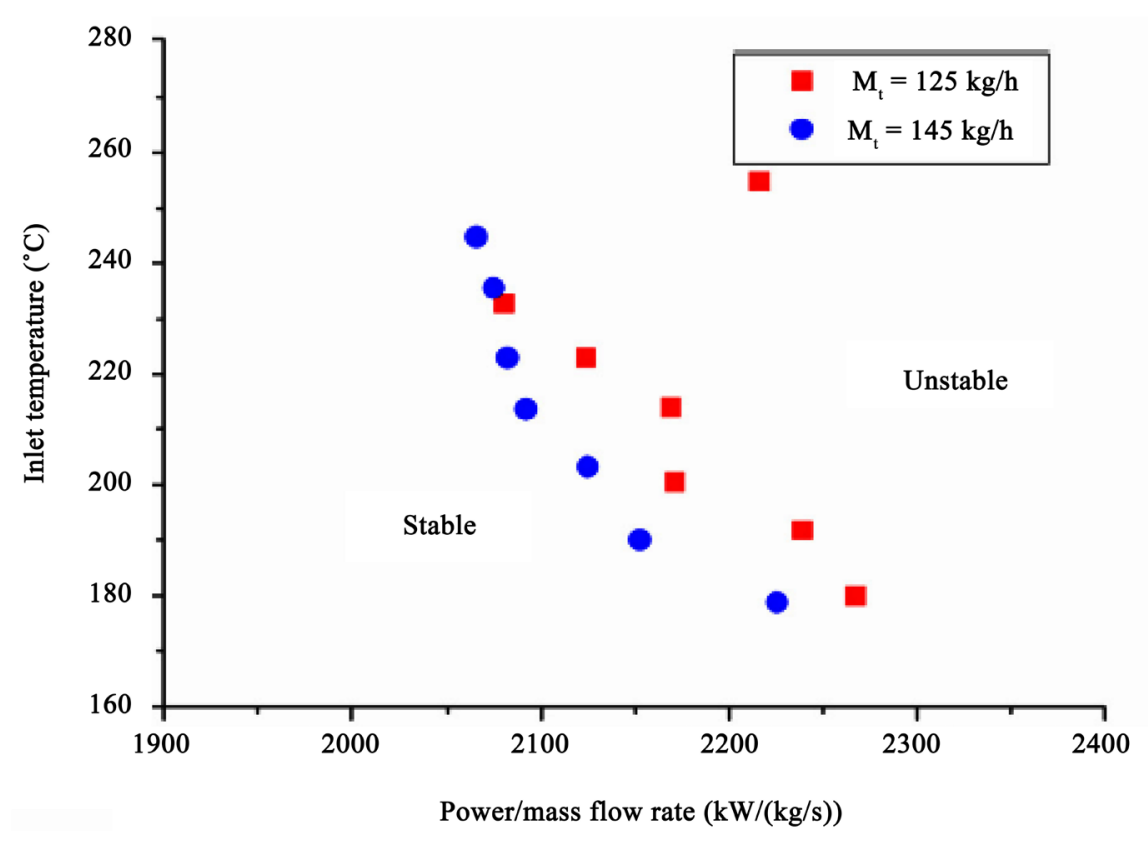

Figure 29. Influence of total inlet mass flow rate on HPBs [11].

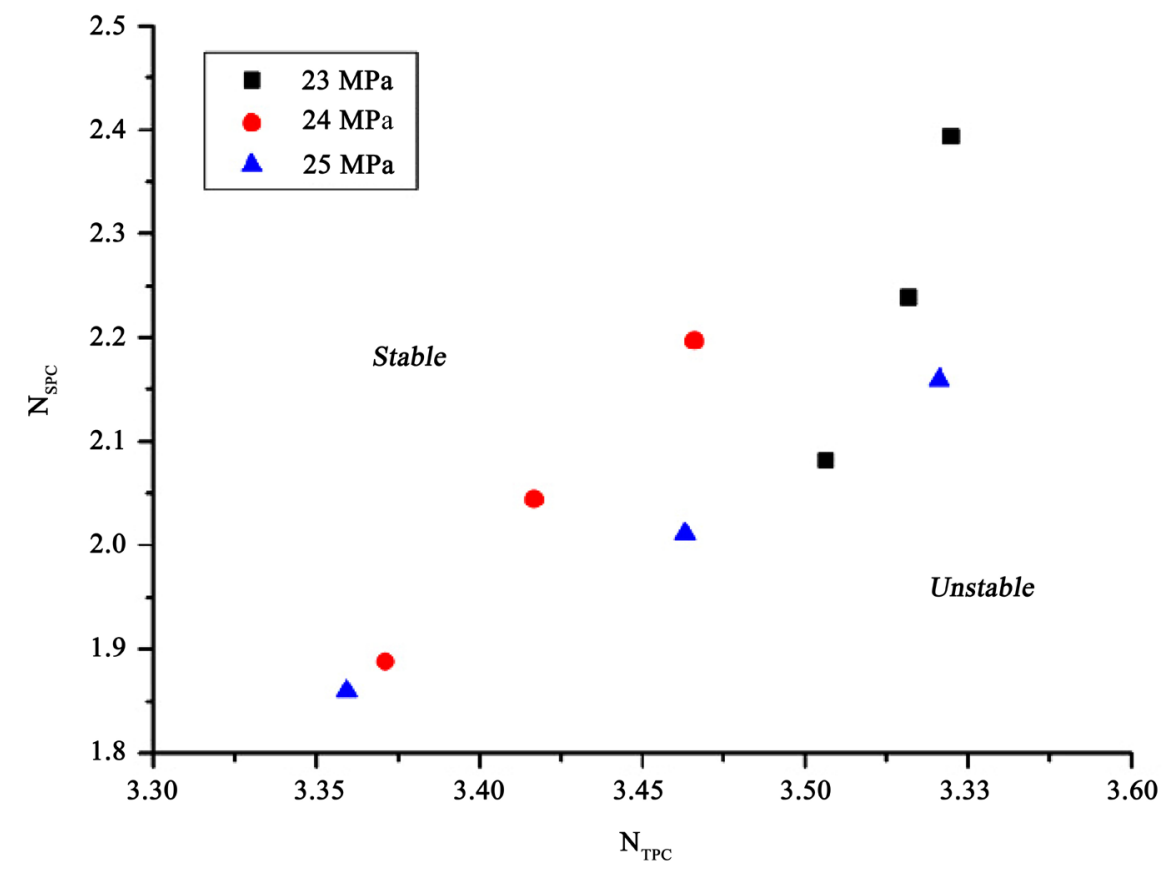

Figure 30. Stability boundaries by experiments [15].

system pressure or inlet temperature and threshold heat flux (Figure 31 \& Figure 32). Their parametric studies show that increase in pressure (Figure 31 and Figure 32) or decrease in coolant inlet temperature (Figure 31 and Figure 32) favors the stability of the coolant flow in the parallel channels.

Zhang et al. [14] investigated two types of DWOs experimentally at supercritical pressures in two parallel channels with supercritical water. They obtained stability boundaries in a two-dimensional plane using two different approaches: 


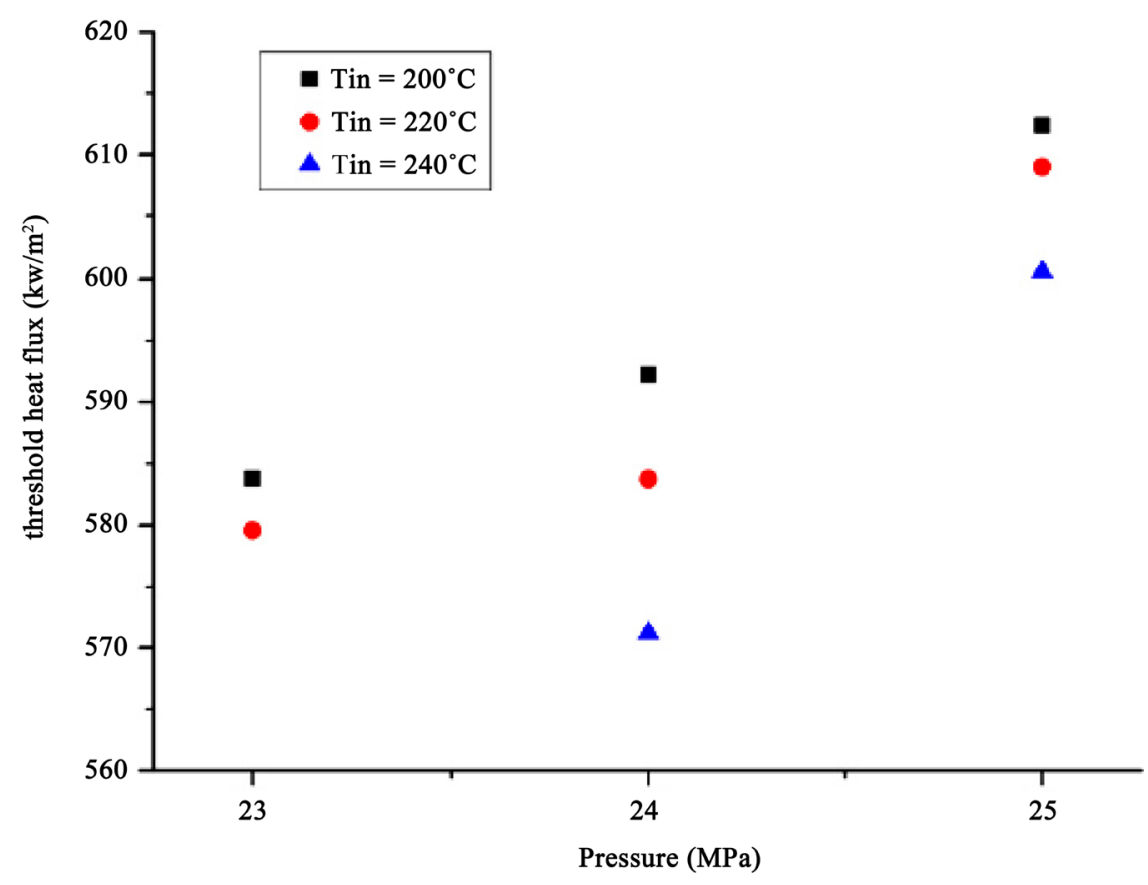

Figure 31. Effect of system pressure on threshold power [15].

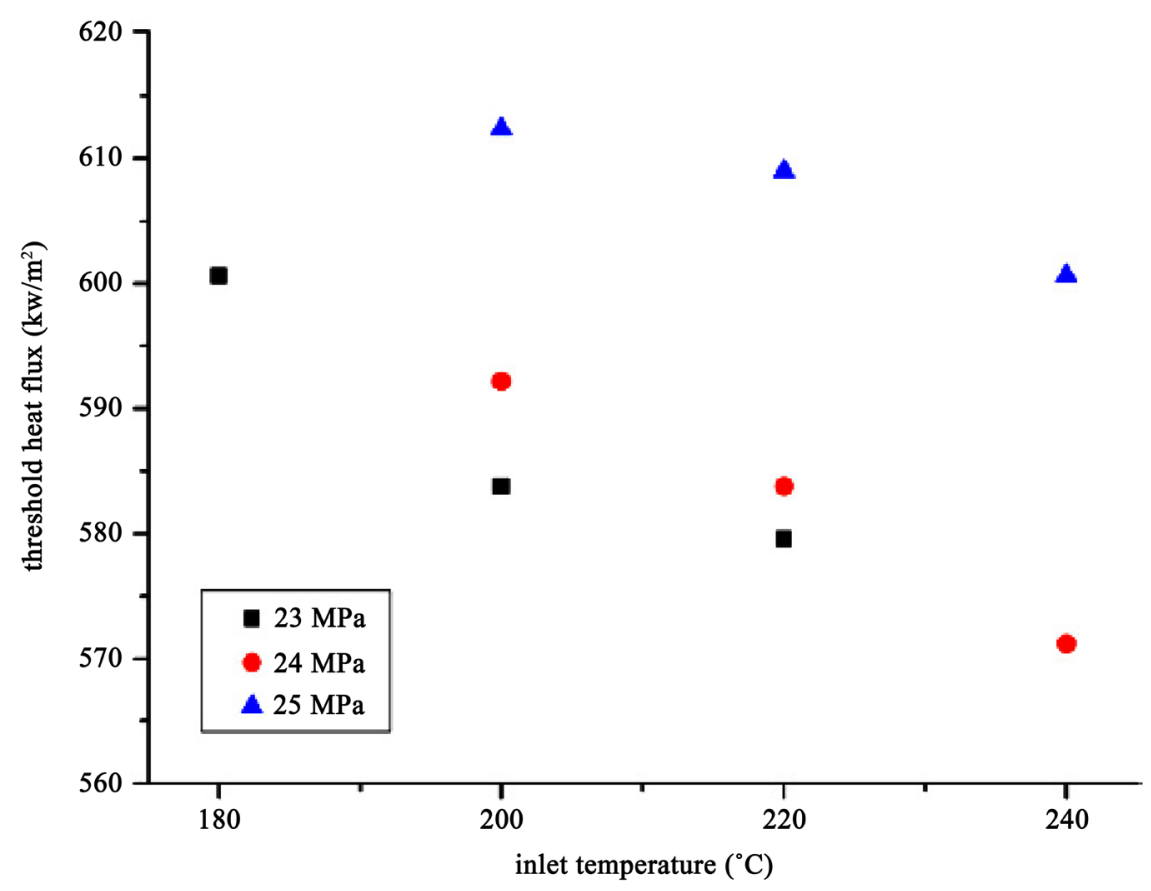

Figure 32. Effect of inlet temperature on threshold power [15].

two ID dimensionless parameters proposed for supercritical flow (Figure 33), and dimensional parameters such as mass flow rate or inlet fluid temperature and boundary heat flux (Figure 34 \& Figure 35). They observed Type I and Type II dynamic instabilities in the parallel channels (Figures 33-39). Type I instability occurs at low heating powers with long period of oscillation (20 - $300 \mathrm{~s})$ whereas type II instability occurs at high heating powers with short period of 


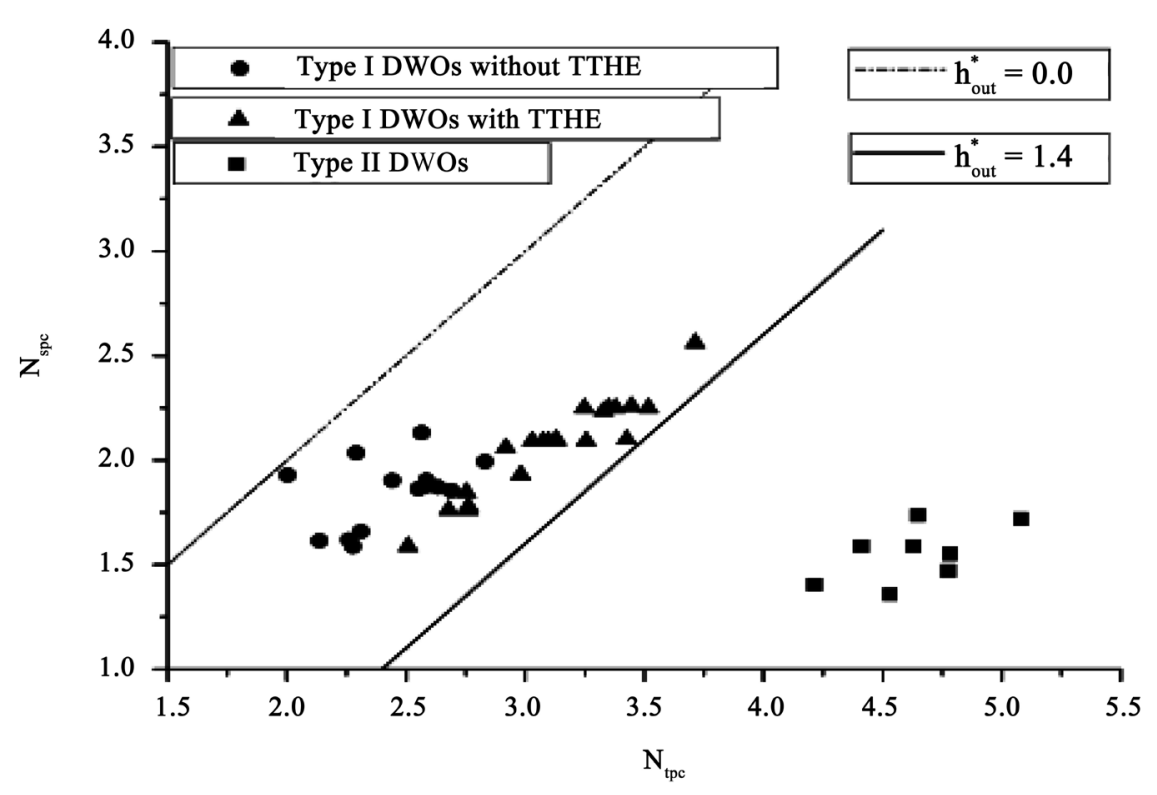

Figure 33. Stability map of supercritical parallel channels [14].

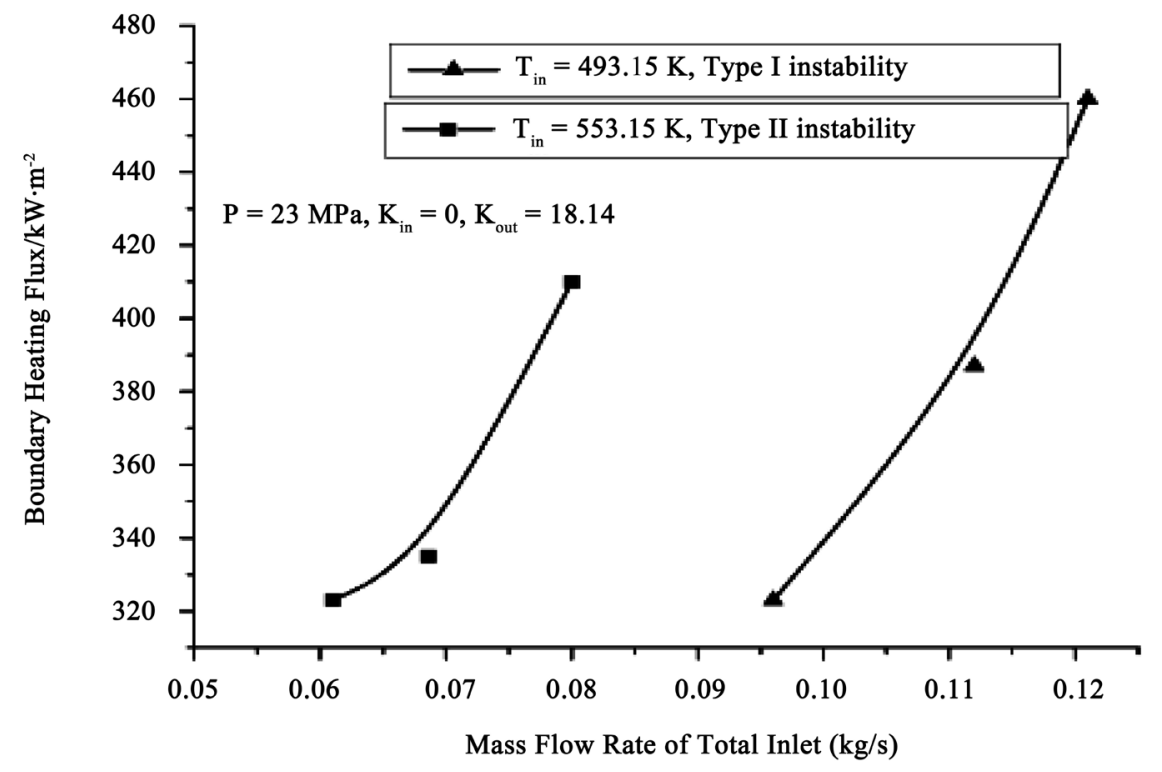

Figure 34. Influence of inlet mass flow rate on instabilities [14].

oscillation (2 - 5 s). Based on stability map drawn using Ambrosini's non-dimensional parameters (Figure 33), it was indicated that flow instability does not occur when the fluid temperature at the exit of the heated channels is below the pseudocritical temperature irrespective of the amount of heating power, inlet temperature, system pressure, and local loss coefficient adopted in the experiment. Zhang et al. observed that flow instability depends only on heating power or heat flux when system geometry and working conditions (mass flow rate, system pressure and inlet temperature) are fixed. They observed also that type I oscillation region, stable region, transit region and type II oscillation region are four different regions the system passes through as a result of increased in heating 


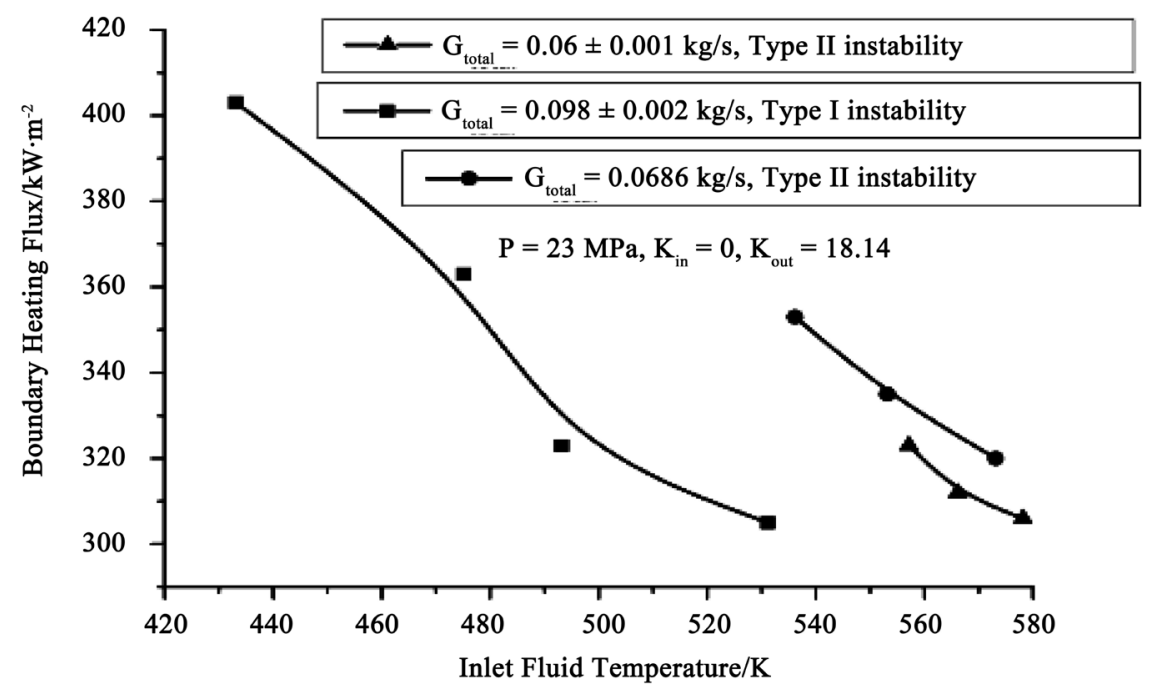

Figure 35. Influence of inlet temperature on instabilities [14].

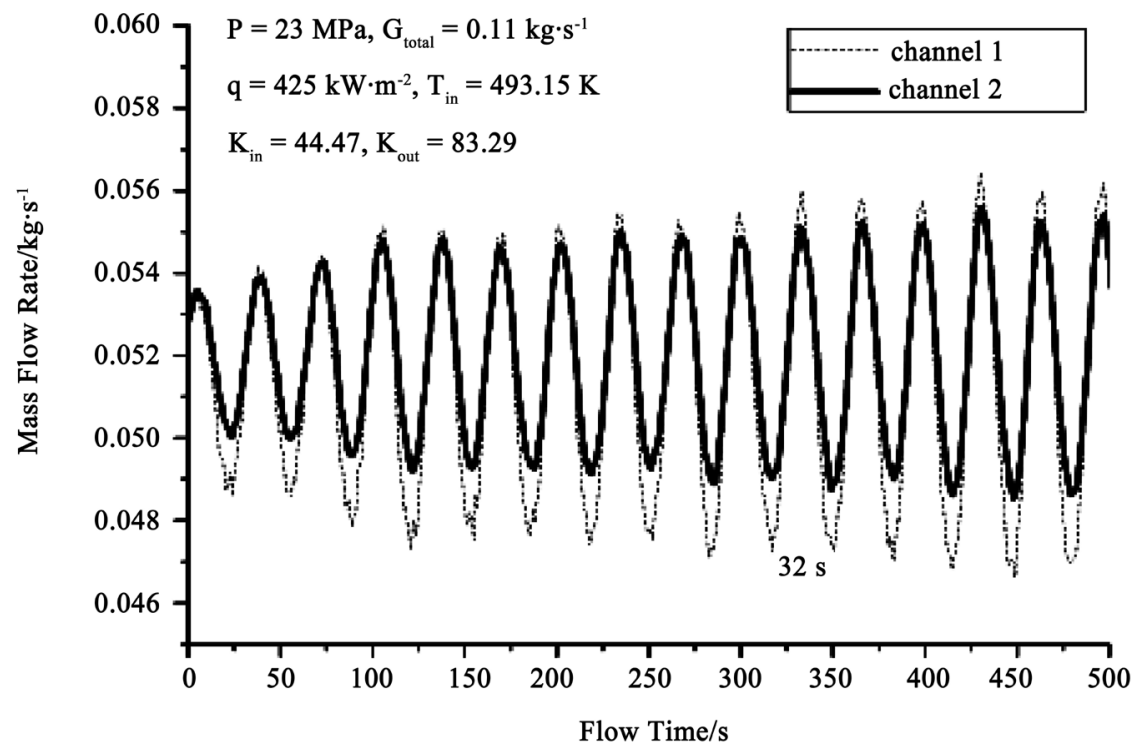

Figure 36. Variation of mass flow rate in parallel channels during type I oscillation [14].

power (Figure 38 and Figure 39). Type 1 instability occurs in region 1 when the fluid outlet temperature goes beyond pseudo-critical point and as a result causing dramatic reduction in fluid density leading to instability in the system. Type 1 instability is characterized by the total inlet flow rate oscillating out of phase with total inlet pressure and also characterized by mass flow rates in channels 1 and 2 oscillating in-phase (Figure 38 and Figure 39). The system is stable in region 2 regardless of the increasing rate of heating power that determines the occurrence of flow instability when the system geometry and working conditions are fixed (Figure 38 and Figure 39). The system is unstable in region 3 (transition region) just like a system with Type I instability but with a relatively smaller periods (20 - $100 \mathrm{~s}$ ) and larger amplitudes (Figure 38 and Figure 39). Type II instability occurs in region 4 when the heating power for transition region is 


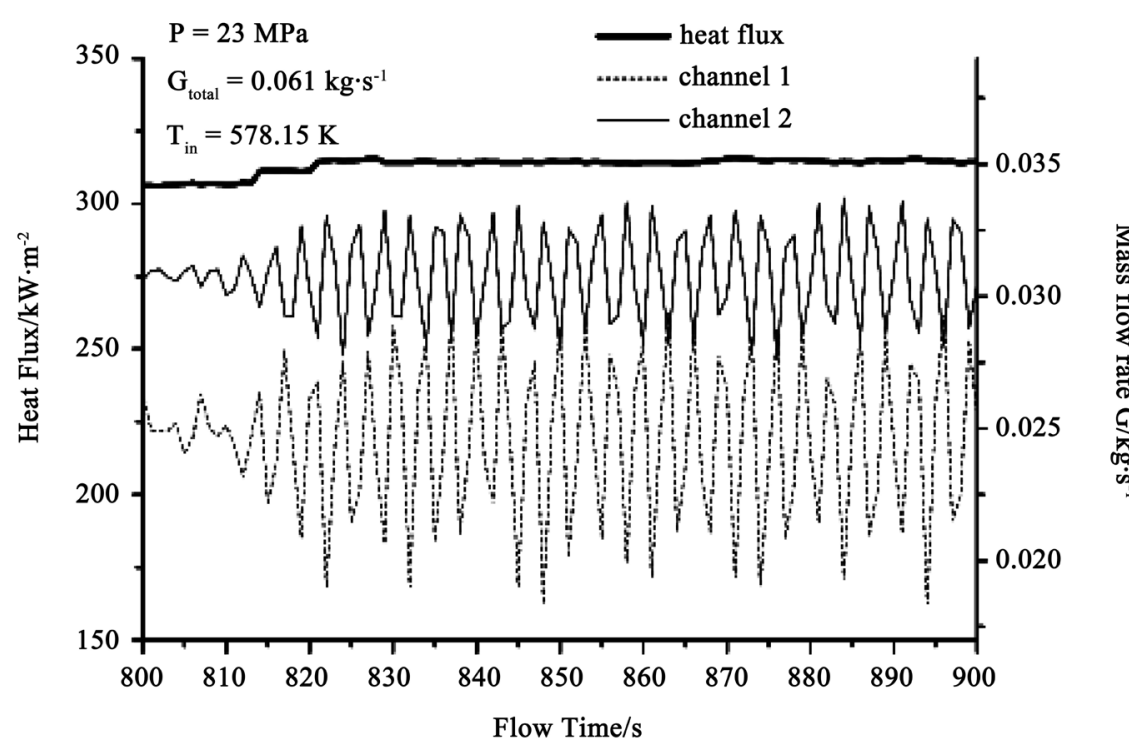

Figure 37. Typical curve of type II instability [14].

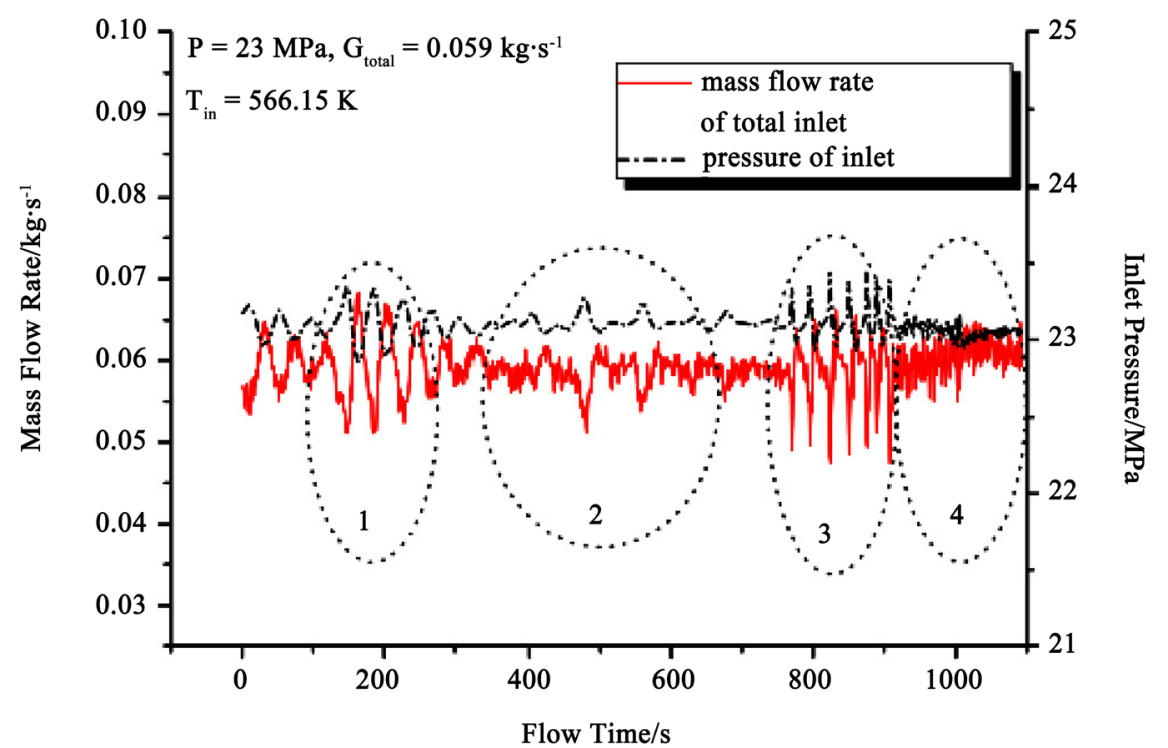

Figure 38. Typical oscillation curves of entrance mass flow rate and system pressure [14].

increased. For Type II instability, the total inlet mass flow rate and pressure are almost constant and the mass flow rate between two channels are $180^{\circ} \mathrm{C}$ out of phase (Figure 38 and Figure 39) [14].

\section{Conclusions}

Research into flow instability at both subcritical and supercritical pressures has attracted attention in recent years because of its potential of occurrence in industrial heat transfer systems. Flow instability has the potential to affect the safety of design and operation of heat transfer equipment. Flow instability is therefore undesirable and should be avoid in the design and operation of industrial equipment. 


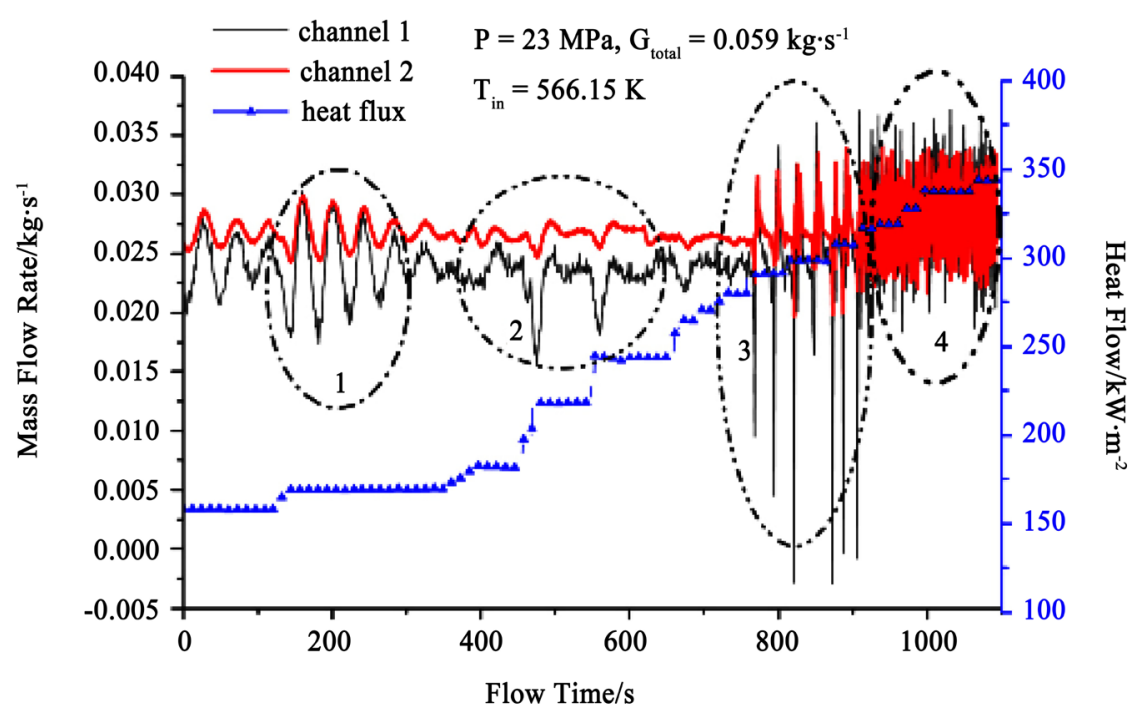

Figure 39. Mass flow rate of individual channels versus time [14].

Rahman et al. reviewed studies on supercritical water heat transfer with the aim of providing references for SCWR researchers. It was found out that most of the CFD studies and experimental studies were performed with single tube geometry due to the complexity of parallel channel geometry. Because studies performed with parallel channel geometry could provide detailed information to the design of the SCWR core, they called for more studies in parallel channel geometry at supercritical pressures in the future. In order to help understand how flow instability investigations are carried out and also highlight the need to understand flow instability phenomenon and equip the designers and operators of industrial heat transfer equipment with the needed knowledge on flow instability, this study carried out a review of flow instability in parallel channels with water at supercritical pressures. The following are the major findings obtained as a result of this review:

- Flow stability for some operating parameters decreases with coolant inlet temperature without any point of inflection. For some operating parameters, there is point of inflection below which flow stability decreases and above which flow stability increases with coolant inlet temperature.

- Flow stability is influenced by operating parameters and the type of axial power shape adopted in heating the walls of the heated sections of the parallel channels.

- An out-of-phase mass flow oscillation is observed in parallel channels when the flow distribution in the channels is no more symmetrical as a result of continuous power perturbation beyond Threshold or Critical or Boundary power of flow instability.

- The entrance and riser sections are important to numerical modeling of flow instability in parallel channels and cannot be eliminated.

- Amplitude of flow oscillation and stability map/diagram developed in terms of dimensionless or dimensional parameters are two main approaches used 
to show whether a system is stable or unstable.

- Two types of dynamic instabilities can occur in parallel channels. Type I instability occurs at low heating powers with long period of oscillation (20 $300 \mathrm{~s}$ ) whereas type II instability occurs at high heating powers with short period of oscillation (2 - $5 \mathrm{~s})$.

- Increase in frictional pressure drop enhances flow stability in parallel channels.

- The lower the power density of the hottest channel, the more stable the system will be.

- More experimental data on flow instability should be provided to help in validation of numerical studies. The design of these experimental studies is helpful in designing similar numerical studies.

\section{References}

[1] Shang, Z. (2009) CFD Investigation of Vertical Rod Bundles of Supercritical WaterCooled Nuclear Reactor. Nuclear Engineering and Design, 239, 2562-2572. https://doi.org/10.1016/j.nucengdes.2009.07.021

[2] Yamaji, A., Oka, Y. and Koshizuka, S. (2005) Three-Dimensional Core Design of High Temperature Supercritical-Pressure Light Water Reactor with Neutronic and Thermal-Hydraulic Coupling. Journal of Nuclear Science and Technology, 42, 8-19. https://doi.org/10.1080/18811248.2005.9726359

[3] Hofmeister, J., Waata, C., Starflinger, J., Schulenberg, T. and Laurien, E. (2007) Fuel Assembly Design Study for a Reactor with Supercritical Water. Nuclear Engineering and Design, 237, 1513-1521. https://doi.org/10.1016/j.nucengdes.2007.01.008

[4] Kitou, K., Koshizuka, S. and Oka, Y. (2001) Refinement of Transient Criteria and Safety Analysis for a High Temperature Reactor Cooled by Supercritical Water. Nuclear Technology, 135, 252-264. https://doi.org/10.13182/NT01-A3220

[5] Oka, Y., Koshizuka, S., Jevremovic, T. and Okano, Y. (1995) Systems Design of Direct-Cycle Supercritical Water Cooled Fast Reactors. Nuclear Technology, 109, 1-10. https://doi.org/10.13182/NT95-A35064

[6] Ambrosini, W. (2007) On the Analogies in the Dynamic Behaviour of Heated Channels with Boiling and Supercritical Fluids. Nuclear Engineering and Design, 237, 1164-1174. https://doi.org/10.1016/j.nucengdes.2007.01.006

[7] Ambrosini, W. (2011) Discussion of Similarity Principles for Fluid-to-Fluid Scaling of Heat Transfer Behaviour at Supercritical Pressures. Nuclear Engineering and Design, 241, 5149-5173. https://doi.org/10.1016/j.nucengdes.2011.08.081

[8] Ampomah-Amoako, E. (2013) Stability and Control of SCWR Systems: A Study into Concepts and Applications. PhD Thesis Submitted to Graduate School, University of Ghana, Legon.

[9] Gómez, T.O. (2009) Stability Analysis of the High Performance Light Water Reactor. Ph.D. Thesis, Forschungszentrum Karlsruhe, Institute for Nuclear and Energy Technologies, University of Karlsruhe.

[10] Sharabi, M.B. (2008) CFD Analyses of Heat Transfer and Flow Instability Phenomena Relevant to Fuel Bundles in Supercritical Water Reactors. PhD Thesis Presented to Dipartimento di Ingegneria Meccanica, Nucleare e della Produzione, Università di Pisa.

[11] Xi, X., Xiao, Z., Yan, X., Li, Y. and Huang, Y. (2014) An Experimental Investigation 
of Flow Instability between Two Heated Parallel Channels with Supercritical Water. Nuclear Engineering and Design, 278, 171-181. https://doi.org/10.1016/j.nucengdes.2014.06.034

[12] Xi, X., Xiao, Z., Yan, X., Xiong, T. and Huang, Y. (2014) Numerical Simulation of the Flow Instability between Two Heated Parallel Channels with Supercritical Water. Annals of Nuclear Energy, 64, 57-66. https://doi.org/10.1016/j.anucene.2013.09.017

[13] Gang, W., Pan J., Bi, Q., Yang, Z. and Wang, H. (2014) Heat Transfer Characteristics of Supercritical Pressure Water in Vertical Upward Annuli. Nuclear Engineering and Design, 273, 449-458. https://doi.org/10.1016/j.nucengdes.2014.03.038

[14] Zhang, L., Cai, B., Weng, Y., Gu, H., Wang, H., Li, H. and Chatoorgoon, V. (2016) Experimental Investigations on Flow Characteristics of Two Parallel Channels in a Forced Circulation Loop with Supercritical Water. Applied Thermal Engineering, 106, 98-108. https://doi.org/10.1016/j.applthermaleng.2016.05.182

[15] Xiong, T., Yan, X., Xiao, Z., Li, Y., Huang, Y. and Yu, J. (2012) Experimental Study on Flow Instability in Parallel Channels with Supercritical Water. Annals of Nuclear Energy, 48, 60-67. https://doi.org/10.1016/j.anucene.2012.05.018

[16] Nayak, A.K. and Vijayan, P.K. (2008) Flow Instabilities in Boiling Two-Phase Natural Circulation Systems: A Review. Science and Technology of Nuclear Installations, 2008, Article ID: 573192. https://doi.org/10.1155/2008/573192

[17] Lange, C. (1979) Advanced Nonlinear Stability Analysis of Boiling Water Nuclear Reactors. PhD Submitted to the Technische Universität Dresden, Fakultät Maschinenwesen, Dohna.

[18] Tong, L.S. and Tang, Y.S. (1997) Boiling Heat Transfer and Two-Phase Flow. 2nd Edition, Taylor \& Francis Publisher, United States of America.

[19] Furuya, M. (2006) Experimental and Analytical Modeling of Natural Circulation and Forced Circulation BWRs - Thermal-Hydraulic, Core-Wide, and Regional Stability Phenomena. Thesis Work Carried at the Department of Radiation, Radionuclides and Reactors (R3), Faculty of Applied Sciences, Delft University of Technology, Mekelweg 15, 2629 JB Delft, The Netherlands.

[20] Ikeda, H., Fukahori, T., Kubo, Y., Soneda, H. and Mizokami, S. (2008) BWR Stability Issues in Japan. Hindawi Publishing Corporation, Science and Technology of Nuclear Installation, Volume 2008, Article ID: 358616.

[21] Jain, P.K. (2006) Numerical Analysis of Supercritical Flow Instabilities in a Natural Circulation Loop. Master's Thesis Submitted to the Graduate College of the University of Illinois at Urbana-Champaign, Urbana, Illinois.

[22] Kakaç, S. and Bon, B. (2008) A Review of Two-Phase Flow Dynamic Instabilities in Tube Boiling Systems. International Journal of Heat and Mass Transfer, 51, 399-433. https://doi.org/10.1016/j.ijheatmasstransfer.2007.09.026

[23] Ruspini, L.C. (2013) Experimental and Numerical Investigation on Two-Phase Flow Instabilities. PhD Thesis Submitted to Faculty of Engineering Science \& Technology, Norwegian University of Science and Technology, Trondheim, Norway.

[24] Yu, L., Sur, A. and Liu, D. (2015) Flow Boiling Heat Transfer and Two-Phase Flow Instability of Nanofluids in a Minichannel. Journal of Heat Transfer, 137, 1-11. https://doi.org/10.1115/1.4029647

[25] Yang, W.S. (2003) SCWR Stability Analysis. 2nd SCWR Information Exchange Meeting, University of Wisconsin, Madison. 
[26] Vijayan, P.K. and Nayak, A.K. (2010) Introduction to Instabilities in Natural Circulation Systems. Joint ICTP-IAEA Course on Natural Circulation Phenomena and Passive Safety Systems in Advanced Water Cooled Reactors.

[27] Gómez, T.O., Class, A., Lahey Jr., R.T. and Schulenberg, T. (2008) Stability Analysis of a Uniformly Heated Channel with Supercritical Water. Nuclear Engineering and Design, 238, 1930-1939. https://doi.org/10.1016/j.nucengdes.2007.10.031

[28] Ambrosini, W. and Sharabi, M.B. (2008) Dimensionless Parameters in Stability Analysis of Heated Channels with Fluids at Supercritical Pressures. Nuclear Engineering and Design, 238, 1917-1929. https://doi.org/10.1016/j.nucengdes.2007.09.008

[29] Zhao, J., Saha, P. and Kazimi, M.S. (2005) Stability of Supercritical Water-Cooled Reactor during Steady-State and Sliding Pressure Start-Up. Proceedings of NURETH-11, Avignon, France.

[30] Hou, D., Lin, M., Liu, P. and Yang, Y. (2011) Stability Analysis of Parallel-Channel Systems with Forced Flows under Supercritical Pressure. Annals of Nuclear Energy, 38, 2386-2396. https://doi.org/10.1016/j.anucene.2011.07.021

[31] Su, Y., Feng, J., Zhao, H., Tian,W., Su, G. and Qiu, S. (2013) Theoretical Study on the Flow Instability of Supercritical Water in the Parallel Channels. Progress in Nuclear Energy, 68, 169-176. https://doi.org/10.1016/j.pnucene.2013.06.005

[32] Xiong, T., Yan, X., Huang, S., Yu, J. and Huang, Y. (2013) Modeling and Analysis of Supercritical Flow Instability in Parallel Channels. International Journal of Heat and Mass Transfer, 57, 549-557. https://doi.org/10.1016/j.ijheatmasstransfer.2012.08.046

[33] Shitsi, E., Debrah, S.K., Agbodemegbe, V.Y. and Ampomah-Amoako, E. (2017) Numerical Investigation of Flow Instability in Parallel Channels with Supercritical Water. Annals of Nuclear Energy, 110, 196-207. https://doi.org/10.1016/j.anucene.2017.06.032

[34] Dutta, G. and Doshi, J.B. (2008) A Characteristics-Based Implicit Finite-Difference Scheme for the Analysis of Instability in Water Cooled Reactors. Nuclear Engineering and Technology, 40, No. 6. https://doi.org/10.5516/NET.2008.40.6.477

[35] Ampomah-Amoako, E. and Ambrosini, W. (2013) Developing a CFD Methodology for the Analysis of Flow Stability in Heated Channels with Fluids at Supercritical Pressures. Annals of Nuclear Energy, 54, 251-262.

https://doi.org/10.1016/j.anucene.2012.11.002

[36] Debrah, S.K., Ambrosini, W. and Chen, Y. (2013) Discussion on the Stability of Natural Circulation Loops with Supercritical Pressure Fluids. Annals of Nuclear Energy, 54, 47-57. https://doi.org/10.1016/j.anucene.2012.10.015

[37] Debrah, S.K., Ambrosini, W. and Chen, Y. (2013) Assessment of a New Model for the linear and Nonlinear Stability Analysis of Natural Circulation Loops with Supercritical Fluids. Annals of Nuclear Energy, 58, 272-285.

https://doi.org/10.1016/j.anucene.2013.03.033

[38] Dutta, G., Zhang, C. and Jiang, J. (2015) Analysis of Parallel Channel Instabilities in the CANDU Supercritical Water Reactor. Annals of Nuclear Energy, 83, 264-273.

https://doi.org/10.1016/j.anucene.2015.04.023

[39] Dutta, G., Zhang, C. and Jiang, J. (2015) Analysis of Flow Induced Density Wave Oscillations in the CANDU Supercritical Water Reactor. Nuclear Engineering and Design, 286, 150-162. https://doi.org/10.1016/j.nucengdes.2015.02.007

[40] Ebrahimnia, E., Chatoorgoon, V. and Ormiston, S.J. (2016) Numerical Stability Analyses of Upward Flow of Supercritical Water in a Vertical Pipe. International Journal of Heat and Mass Transfer, 97, 828-841. 
https://doi.org/10.1016/j.ijheatmasstransfer.2016.02.069

[41] Liu, P., Hou, D., Lin, M., Kuang, B. and Yang, Y. (2014) Stability Analysis of Parallel-Channel Systems under Supercritical Pressure with Heat Exchanging. Annals of Nuclear Energy, 69, 267-277. https://doi.org/10.1016/j.anucene.2014.02.021

[42] Rahman, M.M., Dongxu, J., Beni, M.S., Hei, H.C., He, W. and Zhao, J. (2016) Supercritical Water Heat Transfer for Nuclear Reactor Applications: A Review. Annals of Nuclear Energy, 97, 53-65. https://doi.org/10.1016/j.anucene.2016.06.022

[43] Jingjing, L., Tao, Z., Mingqiang, S., Qijun, H., Yanping, H. and Zejun, X. (2015) CFD Analysis of Supercritical Water Flow Instability in Parallel Channels. International Journal of Heat and Mass Transfer, 86, 923-929. https://doi.org/10.1016/j.ijheatmasstransfer.2015.02.026

[44] Shitsi, E., Debrah, S.K., Agbodemegbe, V.Y. and Ampomah-Amoako, E. (2018) Effect of Axial Power Distribution on Flow Instability in Parallel Channels with Water at Supercritical Pressures. Annals of Nuclear Energy, 112, 109-119.

https://doi.org/10.1016/j.anucene.2017.10.003 